\title{
Neurogenesis-dependent antidepressant-like activity of Hericium erinaceus in an animal model of depression
}

\author{
Pit Shan Chong ${ }^{1 \dagger}$, Chi Him Poon ${ }^{1 \dagger}$, Jaydeep Roy ${ }^{1}, K^{\prime}$ Chun Tsui ${ }^{1}$, Sze Yuen Lew ${ }^{2}$, Michael Weng Lok Phang ${ }^{2}$, \\ Rachael Julia Yuenyinn Tan ${ }^{1}$, Poh Guat Cheng ${ }^{3,4}$, Man-Lung Fung ${ }^{1}$, Kah Hui Wong ${ }^{1,2^{*}}$ and Lee Wei Lim ${ }^{1 *} \mathbb{D}$
}

\begin{abstract}
Background: Depression is a severe neuropsychiatric disorder that affects more than 264 million people worldwide. The efficacy of conventional antidepressants are barely adequate and many have side effects. Hericium erinaceus (HE) is a medicinal mushroom that has been reported to have therapeutic potential for treating depression.

Methods: Animals subjected to chronic restraint stress were given 4 weeks HE treatment. Animals were then screened for anxiety and depressive-like behaviours. Gene and protein assays, as well as histological analysis were performed to probe the role of neurogenesis in mediating the therapeutic effect of HE. Temozolomide was administered to validate the neurogenesis-dependent mechanism of HE.

Results: The results showed that 4 weeks of HE treatment ameliorated depressive-like behaviours in mice subjected to 14 days of restraint stress. Further molecular assays demonstrated the 4-week HE treatment elevated the expression of several neurogenesis-related genes and proteins, including doublecortin, nestin, synaptophysin, brain-derived neurotrophic factor (BDNF), tropomyosin receptor kinase B (TrkB), phosphorylated extracellular signal-regulated kinase, and phosphorylated cAMP response element-binding protein (pCREB). Increased bromodeoxyuridine-positive cells were also observed in the dentate gyrus of the hippocampus, indicating enhanced neurogenesis. Neurogenesis blocker temozolomide completely abolished the antidepressant-like effects of $\mathrm{HE}$, confirming a neurogenesisdependent mechanism. Moreover, HE induced anti-neuroinflammatory effects through reducing astrocyte activation in the hippocampus, which was also abolished with temozolomide administration.
\end{abstract}

Conclusion: HE exerts antidepressant effects by promoting neurogenesis and reducing neuroinflammation through enhancing the BDNF-TrkB-CREB signalling pathway.

Keywords: Hericium erinaceus, Depression, Neurogenesis, Anti-neuroinflammatory, Hippocampus

*Correspondence: wkahhui@um.edu.my; drlimleewei@gmail.com †Pit Shan Chong and Chi Him Poon shared joint-first authorship ${ }^{1}$ Neuromodulation Laboratory, School of Biomedical Sciences, Li Ka Shing Faculty of Medicine, The University of Hong Kong, 21 Sassoon Road, Hong Kong SAR, China

Full list of author information is available at the end of the article

\section{Introduction}

Major depressive disorder is a common mental illness that affects more than 264 million people of all ages worldwide [1]. The symptoms of major depressive disorder include appetite or sleep changes, fatigue, inhibited motivation, feelings of helplessness and hopelessness, loss of interest, self-loathing, and problems with concentrating and decision making [2-4]. Chronic symptoms of depression can affect psychosocial functioning original author(s) and the source, provide a link to the Creative Commons licence, and indicate if changes were made. The images or other third party material in this article are included in the article's Creative Commons licence, unless indicated otherwise in a credit line to the material. If material is not included in the article's Creative Commons licence and your intended use is not permitted by statutory regulation or exceeds the permitted use, you will need to obtain permission directly from the copyright holder. To view a copy of this licence, visit http://creativecommons.org/licenses/by/4.0/. The Creative Commons Public Domain Dedication waiver (http://creativeco mmons.org/publicdomain/zero/1.0/) applies to the data made available in this article, unless otherwise stated in a credit line to the data. 
and can lead to severe emotional, behavioural and physical health problems, and even suicide [2,5]. Depressive disorder is one of the leading causes of the global burden of disease [1]. There are several proposed hypotheses for the pathophysiology of depression, including genetic factors, psychosocial stress, stress hormones, cytokines, monoamine deficiency (including serotonin, norepinephrine and dopamine), altered glutamatergic and GABAergic neurotransmission, and neurogenic and neurotrophic factors that affect brain volume [6]. Various classes of antidepressants have been developed to target different types of depression. Although many conventional antidepressants are available, up to $30 \%$ of patients with major depressive disorder fail to respond to their first prescribed antidepressant and need to be switched to another antidepressant [7]. The reasons for treatment failure often involve suboptimal treatment response or intolerable side effects, including weight gain or sexual dysfunction $[8,9]$. Therefore, novel antidepressants are needed that have higher efficacy but less side effects.

Complementary and alternative medicines can be costeffective treatments for depressive disorders and usually have less side effects [10]. Hericium erinaceus (HE) is a culinary and medicinal mushroom that has been reported to have significant beneficial health effects, including immunomodulatory [11], antitumour [12, 13], antidiabetic [14], antimicrobial [13], antioxidative [15], antihyperglycaemic [16], and hypolipidemic [17] activities. Furthermore, increasing evidence has shown that HE can promote positive nerve and brain health. HE has been shown to possess pharmacological activity that can improve neurological conditions, including cognitive impairment [18], Alzheimer's disease [19], and Parkinson's disease [20]. Recently, HE was shown to ameliorate depressive-like symptoms in both preclinical [21-23] and clinical studies [24-28]. Several pathways have been reported to be involved in the antidepressant effects of HE, including anti-inflammatory pathways [21], neurogenic and neurotrophic modulation [22, 23], and monoamine modulation [23]. The antidepressant effects of $\mathrm{HE}$ can be attributed to various bioactive compounds that can have diverse beneficial functions. Several bioactive compounds extracted from HE have been shown to stimulate the synthesis of nerve growth factor (NGF) and promote neurite outgrowth, which have a role in alleviating depressive-like symptoms [26, 29-35]. Furthermore, an in vivo study reported that $\mathrm{HE}$ enriched with erinacine A could modulate BDNF signalling, and enhance serotonin, dopamine, and noradrenaline expression levels [23]. These studies strongly suggest the antidepressant effects of $\mathrm{HE}$ are mediated through a neurogenesis-dependent mechanism.
Despite evidence showing that HE can potentially alleviate depressive-like symptoms $[21,28]$, the antidepressant-like effects of natural $\mathrm{HE}$ have yet to be examined in an animal model of depression. Therefore, this study aims to investigate the antidepressant-like effects of $\mathrm{HE}$ extracts in a chronic restraint stress (CRS) animal model of depression, and to elucidate the potential neurogenesis mechanisms. We hypothesised that HE would reduce depressive-like behaviours in the animal model of depression through a neurogenesis-dependent pathway.

\section{Experimental section Subjects}

Male C57BL/6 mice (8-10 weeks, $\mathrm{n}=76)$ were housed under controlled conditions $\left(25-27^{\circ} \mathrm{C}\right.$ temperature and $60-65 \%$ humidity) in a 12-h light/dark cycle. Food and water were available ad libitum. All animal procedures were approved by the Committee on the Use of Live Animals in Research (CULATR No. 4495-17), the University of Hong Kong. The animal model of depression was induced by CRS and naïve animals were used as the control.

\section{Extraction and nutritional composition of $\mathrm{H}$. erinaceus}

Hericium erinaceus standardised aqueous extract (NevGro ${ }^{\circledR}$, Batch No. 7H2308X, Ganofarm R\&D Sdn Bhd, Tanjung Sepat, Selangor, Malaysia) was used in this study. Briefly, the extract was prepared from fresh fruiting bodies of HE boiled in reverse osmosis water for $4 \mathrm{~h}$, filtered, concentrated, and spray-dried. The aqueous extract consisted of $20.66 \%$ beta $1,3-1,6$ glucan and $0.17 \%$ adenosine (Nova Laboratories Private Limited, Sepang, Selangor, Malaysia). Total glucan and $\alpha$-glucan were quantified by a $\beta$-glucan assay kit (Megazyme International, Wicklow, Ireland). Adenosine content was analysed and measured by high-performance liquid chromatography (HPLC) using an in-house method (Nova Laboratories Private Limited, Sepang, Selangor, Malaysia) [36].

\section{Extraction, isolation, and identification of $\mathrm{H}$. erinaceus compounds}

Hericium erinaceus was macerated and extracted with 95\% ethanol. The extract was concentrated in vacuo and subjected to isolation methods based on size exclusion and polarity chromatography. In the size exclusionbased method, the ethanol extract was fractionated using gel permeation chromatography (Sephadex LH-20, GE Healthcare, Uppsala, Sweden) with methanol $(\mathrm{MeOH})$ into 10 fractions, from which compound $\mathbf{1}$ was derived from the 8th fraction. In the polarity-based method, the ethanol extract was subjected to liquid-liquid partitioning between $\mathrm{n}$-butanol and water. The $\mathrm{n}$-butanol fraction was fractionated using preparative radial chromatography 
with silica gel (Silica gel $60 \mathrm{PF}_{254}$, Merck, Darmstadt, Germany). The solvent system used in preparative radial chromatography was chloroform $\left(\mathrm{CHCl}_{3}\right)$ and $1-15 \%$ $\mathrm{MeOH}-\mathrm{CHCl}_{3}$. The preparative radial chromatography procedure was repeated for three runs to give 10 to 13 fractions. The 6th fraction from the first run and the 5th fraction from the second and third runs were combined for further processing by preparative radial chromatography with silica gel and mobile phase of ether $\left(\mathrm{Et}_{2} \mathrm{O}\right)$ with an increasing $\mathrm{MeOH}$ gradient. Compound 2 was obtained from the 4th-6th fractions $(8.6 \mathrm{mg})$ [37] and a medium polar compound 3 was obtained from the 2nd and 3rd fractions ( $3 \mathrm{mg}$ ). Additional file 1: Fig. S1B shows the steps involved in the isolation of the compounds. The compounds were analysed using spectroscopic methods: ${ }^{1} \mathrm{H}$ and ${ }^{13} \mathrm{C}$ nuclear magnetic resonance (NMR) spectra were recorded in $\mathrm{MeOH}_{-}$d4 on an FT-NMR Avance III $600 \mathrm{MHz}$ (Bruker, Massachusetts, USA), high-resolution electrospray ionisation mass spectrometry (HRESIMS) data were obtained on an Agilent 6530 Q-TOF mass spectrometer (Agilent Technologies, California, USA), Ultraviolet (UV) spectra were obtained on a Shimadzu UV-2600 spectrophotometer (Shimadzu, Kyoto, Japan), and Infrared (IR) spectra were recorded on a Spectrum 400 FT-IR/FT-FIR spectrophotometer (PerkinElmer, Massachusetts, USA) [37, 38].

\section{Determination of total polyphenol content}

HE was dissolved in $80 \%$ methanol $(\mathrm{MeOH})$ at a ratio of 1:4 (w/v) with shaking for $30 \mathrm{~min}$. The extract was centrifuged at $6500 \mathrm{rpm}$ for $15 \mathrm{~min}$ at $4{ }^{\circ} \mathrm{C}$ in a refrigerated centrifuge (Sorvall ST 16R; Thermo Fisher Scientific, Waltham, Massachusetts, USA). The supernatant $(10 \mu \mathrm{L})$ or gallic acid standard solution was mixed with $790 \mu \mathrm{L}$ double-distilled water $\left(\mathrm{ddH}_{2} \mathrm{O}\right)$ and $5 \mu \mathrm{L}$ Folin-Ciocalteu reagent. After $1 \mathrm{~min}, 150 \mu \mathrm{L}$ sodium carbonate was added to the mixture and incubated for $2 \mathrm{~h}$ at room temperature in the dark. Absorbance was measured at $750 \mathrm{~nm}$ using a spectrophotometer (Eppendorf BioSpectrometer basic; Eppendorf, Hamburg, Germany) with gallic acid as the reference standard. Total polyphenol content was expressed as milligram gallic acid equivalent per gram of extract (mg GAE/g) [39, 40].

\section{Determination of total flavonoid content}

HE was dissolved in $80 \%$ methanol $(\mathrm{MeOH})$ at a ratio of $1: 4(\mathrm{w} / \mathrm{v})$ with shaking for $30 \mathrm{~min}$. The extract was centrifuged at $6500 \mathrm{rpm}$ for $15 \mathrm{~min}$ at $4{ }^{\circ} \mathrm{C}$ in a refrigerated centrifuge (Sorvall ST 16R; Thermo Fisher Scientific, Waltham, Massachusetts, USA). The supernatant

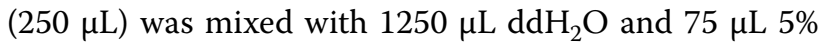
sodium nitrite $\left(\mathrm{NaNO}_{2}\right)$ at room temperature. After 5 min, $150 \mu \mathrm{L} 10 \%$ aluminium chloride $\left(\mathrm{AlCl}_{3}\right)$ was added into the mixture and incubated for $5 \mathrm{~min}$ at room temperature. After incubation, $500 \mu \mathrm{L} 1 \mathrm{M}$ sodium hydroxide $(\mathrm{NaOH})$ and $275 \mu \mathrm{L} d d \mathrm{H}_{2} \mathrm{O}$ were added to the mixture. Absorbance was measured at $510 \mathrm{~nm}$ using a spectrophotometer (Eppendorf BioSpectrometer basic; Eppendorf, Hamburg, Germany) with catechin as the reference standard. Total flavonoid content was expressed as milligram catechin equivalent per gram of extract $(\mathrm{mg} \mathrm{CE} / \mathrm{g})$ $[41,42]$.

\section{Determination of total antioxidant capacity}

$\mathrm{HE}$ was dissolved in $80 \%$ methanol $(\mathrm{MeOH})$ at a ratio of 1:4 (w/v) with shaking for $30 \mathrm{~min}$. The extract was centrifuged at $6500 \mathrm{rpm}$ for $15 \mathrm{~min}$ at $4{ }^{\circ} \mathrm{C}$ in a refrigerated centrifuge (Sorvall ST 16R; Thermo Fisher Scientific, Waltham, Massachusetts, USA). The supernatant $(5 \mu \mathrm{L})$ was mixed with $95 \mu \mathrm{L} 80 \% \mathrm{MeOH}$ in $1000 \mu \mathrm{L}$ reagent (0.6 M sulphuric acid, $28 \mathrm{mM}$ sodium phosphate, and $4 \mathrm{mM}$ ammonium molybdate) and incubated for $90 \mathrm{~min}$ at $95{ }^{\circ} \mathrm{C}$ in the dark. After incubation, the mixture was cooled to room temperature and absorbance was measured at $695 \mathrm{~nm}$ using a spectrophotometer (Eppendorf BioSpectrometer basic; Eppendorf, Hamburg, Germany) with ascorbic acid as the reference standard. Total antioxidant capacity was expressed as microgram ascorbic acid equivalent per gram of extract (mg AAE/g) [40, 43].

\section{DPPH free radical scavenging assay}

A $20 \mu \mathrm{g} / \mathrm{mL}$ 2,2-diphenyl-1-picrylhydrazyl (DPPH) solution was first prepared in $99.8 \%$ ethanol (EtOH). Next, $2 \mathrm{~mL}$ DPPH solution was added to $1 \mathrm{~mL} \mathrm{HE}$ dissolved in $\mathrm{ddH}_{2} \mathrm{O}$ and incubated for $20 \mathrm{~min}$ at room temperature in the dark. Absorbance was measured at $517 \mathrm{~nm}$ using a multimode plate reader (EnSpire ${ }^{\mathrm{TM}}$ 2300; PerkinElmer, Waltham, Massachusetts, USA). The scavenging activity was calculated using the following formula: \% Activity $=[1-($ sample absorbance / blank absorbance $)] \times 100$. The scavenging activity was expressed as $\mathrm{EC}_{50}(\mathrm{mg} /$ $\mathrm{mL}$ ), which is the effective concentration at which $50 \%$ of DPPH radicals are scavenged [44]. Ascorbic acid was used as the positive control.

\section{Ferric reducing antioxidant power (FRAP) assay}

The FRAP reagent was prepared by mixing $300 \mathrm{mM}$ acetate buffer, $20 \mathrm{mM}$ ferric chloride hexahydrate $\left(\mathrm{FeCl}_{3} \cdot 6 \mathrm{H}_{2} \mathrm{O}\right)$, and $10 \mathrm{mM}$ tripyridyltriazine (TPTZ) in $\mathrm{ddH}_{2} \mathrm{O}$. Next, $25 \mu \mathrm{L} \mathrm{HE}$ in $\mathrm{ddH}_{2} \mathrm{O}$ was mixed with $175 \mu \mathrm{L}$ FRAP reagent and incubated for $4 \mathrm{~min}$ at room temperature. Absorbance was measured at $593 \mathrm{~nm}$ using a multimode plate reader (EnSpire ${ }^{\mathrm{TM}}$ 2300; PerkinElmer, Waltham, Massachusetts, USA) with ferrous sulphate $\left(\mathrm{FeSO}_{4} \cdot 7 \mathrm{H}_{2} \mathrm{O}\right)$ as the reference standard. The change in absorbance was calculated by the following formula: 
Sample absorbance - (sample blank absorbance + reagent absorbance). The FRAP value was expressed as micromole ferrous sulphate equivalent per gram of extract ( $\mu \mathrm{mol} \mathrm{FeSO}_{4} \cdot 7 \mathrm{H}_{2} \mathrm{O}$ equivalents/g) [45]. Ascorbic acid was used as the positive control.

\section{Screening for gene targets of $\mathrm{HE}$, depression, and $\mathrm{HE}$-depression overlap}

HE contains Hericenone class compounds, Erinacine class compounds, ergosterol peroxide, and cerevisterol [28]. Additionally, our previous findings indicated that HE also contains adenosine and herierin III [37]. We used PubChem database (http://pubchem.ncbi.nlm.nih.gov) to search for corresponding gene targets of the compounds in HE. The gene ID and the gene name were retrieved by the subsequent procedures. For depression-related gene search, we performed the gene-target search using DisGeNET (http://www.disgenet.org), a database of genedisease associations. We used the search term "Mental Depression" (UMLS CUI:C0011570) for the retrieval of gene targets. A total of 1478 of genes were initially returned, of which 261 genes remained after applying a filter of Score $_{\text {gda }} \geq 0.1$ and $\mathrm{EI}_{\text {gda }}=1$. We then compared the gene lists from PubChem and DisGeNET to select replicated genes for the further downstream analyses.

\section{Network construction, gene ontology and KEGG pathway enrichment analysis}

A compound-target network based on the PubChem results was constructed with Cytoscape V3.8.2, a software for network visualization. To examine the association between $\mathrm{HE}$ and depression at the genome level, gene ontology (GO) enrichment and Kyoto Encyclopedia of Genes and Genomes (KEGG) pathway analysis were performed in $\mathrm{R}$ (Version 2021.09.0) using the Bioconductor package (http://www.bioconductor.org/). All HE-depression overlapped genes were first converted to EntrezID. Genes were then annotated with ClusterProfiler and "Homo sapiens" genome library for the corresponding GO terms, and the results were visualized by ggplot2. The GO analysis consisted of three aspects: Biological Process (BP), Cellular Component (CC), and Molecular Function (MF). Only the top 10 results with $\mathrm{p}$-value $\leq 0.01$ in each aspect were enriched and visualized. The HE-depression overlapped genes were also analysed by KEGG to examine the relationship of HE and depression in terms of the molecular pathways. Results from GO analysis and KEGG are presented in the dotplot and pathview diagrams.

\section{Experimental design and drug administration}

The model of depression was generated by subjecting animals to CRS with immobilisation for $6 \mathrm{~h}$ per day, continuously for a total of 14 days. Animals received daily injection of $\mathrm{HE}$ at experimental doses of 10 and $25 \mathrm{mg} /$ $\mathrm{kg}$ or $0.9 \%$ saline intraperitoneally for 4 weeks. The control non-CRS animals were injected with $0.9 \%$ saline. On days 8,10 , and 12, Bromodeoxyuridine (BrdU; $150 \mathrm{mg} /$ kg; Sigma-Aldrich, Missouri, USA) was intraperitoneally injected to monitor cell proliferation and neurogenesis in the animal brain. Temozolomide (TMZ) was used to block hippocampal neurogenesis and was injected in the first 3 weeks (days 1, 3, 5, 8, 10, 12, 15, 17, 19, 22, 24, and 26). A battery of behavioural tests was applied: cage emergence test and novelty-suppressed feeding test to assess anxiety, and sucrose preference test and tail suspension test to evaluate depressive-like behaviours. For details of the experimental design, see Fig. 3A.

\section{Behavioural testing}

All behavioural tests were performed as previously described with minor modifications [46]. For the cage emergence test, animals were individually placed in an aversive cage with light (450 Lux) shining on the cage. A grid was placed in the open cage to allow the animals to escape the cage. Their movement was recorded by video to determine the latency to escape from the cage. For the novelty-suppressed feeding test, an open field $(40 \times 40 \times 40 \mathrm{~cm})$ was used to evaluate the animal's aversion to eating in a novel environment. The animal was deprived of food but allowed access to water for $24 \mathrm{~h}$ prior to testing. The animal was placed on the edge of a brightly lit open field with a petri dish of rodent chow located in the centre of the field. Latency to feed was recorded within $10 \mathrm{~min}$ to assess the level of anxiety. For the sucrose preference test, animals were housed individually and pre-exposed to $1 \%$ sucrose solution without water for $1 \mathrm{~h}$. Prior to testing, animals were restricted to food and water for $14 \mathrm{~h}$. A bottle of pre-weighed 1\% sucrose solution and a bottle of pre-weighed water were provided to the animal for $2 \mathrm{~h}$. Sucrose intake and water intake were recorded by weight. The sucrose preference index as a measure of stress-induced anhedonia was calculated using the following formula: Sucrose preference $(\%)=($ sucrose intake $) /($ water intake + sucrose intake $)$ $\times 100 \%$. For the tail suspension test, the animal was suspended in a suspension box ( $40 \mathrm{~cm}$ high) by taping the tail to the top of the box using adhesive tape. Their movement was video recorded to measure the immobility time during the 5-min test. 


\section{Tissue processing}

The animals were euthanised with sodium pentobarbital (Dorminal, Alfasan International BV, Woerden, Holland). Animals were decapitated and their extracted brains were immediately frozen in liquid nitrogen and stored at $-80{ }^{\circ} \mathrm{C}$ for the gene and protein expression studies.

\section{Real-time PCR}

The dorsal hippocampus was dissected to examine the expression levels of neurogenesis-related genes. Realtime PCR was performed according to previously published methodology $[47,48]$. Total RNA was isolated from the hippocampus using TRIZOL (Life Technologies, Carlsbad, USA) and converted into cDNA using a cDNA synthesis kit (Takara Bio Inc., Shiga, Japan). Quantitative real-time PCR (qPCR) of neurogenesis- and neuroplasticity-related genes including brain-derived neurotrophic factor (Bdnf), tropomyosin receptor kinase $B$ (Trkb), neuronal nuclei (Neun), doublecortin (Dcx), synapsin (Syn), nestin (Nes), cAMP response element-binding protein (Creb), and postsynaptic density-95 (Psd-95) were performed using the StepOnePlus Real-Time PCR system (Thermo Fisher Scientific, Massachusetts, USA) with SYBR Green quantitative PCR mix (Applied Biosystems, Warrington, UK). The primer sequences used in this study can be found in Table 1 . The relative expression was calculated as the relative quantification normalised to the reference glyceraldehyde 3-phosphate dehydrogenase (Gapdh) gene using the ratio $2^{-\Delta \Delta C}$ method $[47,49]$.

Table 1 The primer sequences used in the real-time quantitative PCR

\begin{tabular}{|c|c|}
\hline Gene & $5^{\prime}-3^{\prime}$ primer sequence \\
\hline$B d n f[104]$ & $\begin{array}{l}\text { Forward: TGGCTGACACTTTTGAGCAC } \\
\text { Reverse: AAGTGTACAAGTCCGCGTCC }\end{array}$ \\
\hline $\operatorname{TrkB}[105]$ & $\begin{array}{l}\text { Forward: CCTCCACGGATGTTGCTGAC } \\
\text { Reverse: GCAACATCACCAGCAGGCA }\end{array}$ \\
\hline NeuN [106] & $\begin{array}{l}\text { Forward: GAGGAGTGGCCCGTTCTG } \\
\text { Reverse: AGGCGGAGGAGGGTACTG }\end{array}$ \\
\hline$D c x[107]$ & $\begin{array}{l}\text { Forward: ACACCCTTGATGGAAAGCAG } \\
\text { Reverse: AGGACCACAAGCAATGAACA }\end{array}$ \\
\hline SYP [108] & $\begin{array}{l}\text { Forward:TGTGTTTGCCTTCCTCTACTC } \\
\text { Reverse: TCAGTGGCCATCTTCACATC }\end{array}$ \\
\hline Nes [109] & $\begin{array}{l}\text { Forward: AGGCTGAGAACTCTCGCTTGC } \\
\text { Reverse: GGTGCTGGTCCTCTGGTATCC }\end{array}$ \\
\hline Creb [110] & $\begin{array}{l}\text { Forward: CAGGGGTCGCAAGGATTGAAG } \\
\text { Reverse: ATCGCCTGAGGCAGTGTACT }\end{array}$ \\
\hline Psd-95 [111] & $\begin{array}{l}\text { Forward: GACGCCAGCGACGAAGAG } \\
\text { Reverse: CTCGACCCGCCGTTTG }\end{array}$ \\
\hline Gapdh (47) & $\begin{array}{l}\text { Forward: GTCGGTGTGAACGGATTTG } \\
\text { Reverse: AATTTGCCGTGAGTGGAGTC }\end{array}$ \\
\hline
\end{tabular}

\section{Protein preparation and Western blot analysis}

The dorsal hippocampus was homogenised with RIPA buffer containing protease and phosphatase inhibitors (Thermo Scientific, Rockford, Illinois, USA). The protein concentration was measured by Bio-Rad DC Protein Assay Kit (Bio-Rad, Hercules, California, USA). The samples were separated by $8-12 \%$ SDS-PAGE and transferred to PVDF membranes (Bio-Rad Laboratories, Hercules, California, USA) using a semi-dry electroblotting system. The membranes were blocked with 5\% BSA in TBS-T (20 mM Tris-HCl, $150 \mathrm{mM} \mathrm{NaCl}, 0.1 \%$ Tween 20) for $1 \mathrm{~h}$ at room temperature. Blots were incubated at $4{ }^{\circ} \mathrm{C}$ overnight with respective primary antibodies, including TrkB, pTrkB (1:1000; Millipore, Massachusetts, USA), pCREB (1:500; Cell Signaling Technology, Inc., Beverly, Massachusetts, USA), CREB, ERK1/2, pERK1/2, GAPDH (1:1000; Cell Signaling Technology, Inc., Massachusetts, USA), and BDNF (1:1000; Abcam, Cambridge, Massachusetts, USA). Horseradish peroxidase-conjugated antirabbit immunoglobulin $\mathrm{G}$ antibody (Invitrogen, Thermo Fisher Scientific, Massachusetts, USA) was added for $1 \mathrm{~h}$ at room temperature. Bound proteins were visualised by chemiluminescence kit (Bio-Rad Laboratories, Inc., Hercules, California, USA) and the relative protein expression level was normalised against GAPDH.

\section{Immunofluorescence staining}

Animals were sacrificed and transcardially perfused with 4\% paraformaldehyde. Brain tissue was extracted and post-fixed in $4 \%$ paraformaldehyde with cryoprotection in $15 \%$ and $30 \%$ sucrose solution until the tissues sank to the bottom. Brain tissues were snap-frozen in liquid nitrogen before storing in a $-80{ }^{\circ} \mathrm{C}$ freezer. Coronal sections were obtained in a CryoStar NX50 Cryostat (Thermo Fisher Scientific, Massachusetts, USA). Brain sections were blocked with $3 \% \mathrm{H}_{2} \mathrm{O}_{2}$ solution before pretreating with $2 \mathrm{~N} \mathrm{HCl}$ for $30 \mathrm{~min}$ at $37{ }^{\circ} \mathrm{C}$. After blocking with 5\% BSA for $30 \mathrm{~min}$, sections were incubated with anti-BrdU (1:500; ab6326, Abcam, Cambridge, Massachusetts, USA) and anti-NeuN (1:1000; MAB377, Millipore, Massachusetts, USA) at $4{ }^{\circ} \mathrm{C}$ overnight. Sections were incubated with goat anti-rat IgG Dylight 488 (1:1000; ab150157, Abcam, Cambridge, Massachusetts, USA) and goat anti-mouse IgG Alexa Fluor 546 (1:1000; A-11003, Invitrogen, Thermo Fisher Scientific, Massachusetts, USA). Sections were counterstained with DAPI, and images were acquired using an Olympus BX53 Fluorescence microscope.

\section{Immunohistochemistry}

Brain sections were obtained as described above. Brain sections were blocked with $0.5 \% \mathrm{H}_{2} \mathrm{O}_{2}$ solution and $1 \%$ BSA and then incubated with anti-GFAP (1:1000; 561483, 
BD Biosciences, San Diego, California, USA) at $4{ }^{\circ} \mathrm{C}$. Sections were incubated with biotinylated horse anti-goat IgG (1:1000; BA9500, Vector Laboratories, California, USA) and horse anti-mouse IgG (1:1000; BA-2000, Vector Laboratories). Sections were counterstained with haematoxylin and images were acquired using a bright-field microscope with cellSens imaging software (Olympus, Japan).

\section{Statistical analysis}

Statistical analyses were performed using IBM SPSS Statistics 25. All data were screened for normal distribution. Results for antioxidant capacity, scavenging assay, and FRAP assay were analysed by independent sample t-test with $p<0.001$ considered statistically significant. Data from behavioural tests, gene assays, Western blot analysis, and immunohistochemistry and immunofluorescence staining were analysed by one-way ANOVA with LSD post-hoc test for multiple detailed comparisons among CRS groups. Student's t-test was used for the comparison between non-CRS control group and CRS + saline group to verify the effective induction of depressive behaviour. Dunnett's multiple comparison was used for comparisons with the non-CRS control group. All data was presented as mean \pm S.E.M. and $p \leq 0.05$ was considered statistically significant.

\section{Results}

\section{Phytochemical content and in vitro antioxidant activities of $\mathrm{HE}$}

Table 2 shows the phytochemical constituents and in vitro antioxidant activities of HE. The total polyphenol and flavonoid constituents were $2.26 \pm 0.20 \mathrm{mg}$ GAE/g and $0.73 \pm 0.03 \mathrm{mg} \mathrm{CE} / \mathrm{g}$, respectively. The antioxidant activities as measured by total antioxidant capacity was $7.79 \pm 0.43 \mathrm{mg} \mathrm{AAE} / \mathrm{g}$. The DPPH free radical scavenging activity $\left(\mathrm{EC}_{50}\right)$ was $1.44 \pm 0.05 \mathrm{mg} / \mathrm{mL}$. The ferric reducing antioxidant power (FRAP) was $52.34 \pm 4.82 \mu \mathrm{mol}$ $\mathrm{FeSO}_{4} \cdot 7 \mathrm{H}_{2} \mathrm{O}$ equivalents/g.

\section{Isolation and structural elucidation of HE compounds}

Figure 1 shows the chemical structures of compounds isolated from HE, namely adenosine (1), herierin III (2) and herierin IV (3). Adenosine is a white powder and herierin III is a colourless oil [37]. Herierin IV ( $3 \mathrm{mg}$, $0.005 \%$ ) was isolated as a colourless oil. The UV spectrum showed absorption peaks $\left(\lambda_{\max }\right)$ at 224.50 and $250.50 \mathrm{~nm}$, suggesting a pyrone chromophore. The IR spectrum revealed peaks at 3348.05 and $1659.81 \mathrm{~cm}^{-1}$ due to the presence of $\mathrm{OH}$ group and unsaturated ketone functionalities, respectively. The HRESIMS showed an $[\mathrm{M}+\mathrm{H}]^{+}$ peak at $m / z$ 171.0658, revealing the molecular formula of herierin IV as $\mathrm{C}_{8} \mathrm{H}_{10} \mathrm{O}_{4}$. The complete NMR data assignments of herierin IV is summarised in Additional file 1: Fig. S1 and Additional file 2: Table S1.

\section{Prediction analysis of the pharmacological mechanism of $\mathrm{HE}$ based on network pharmacology}

To probe the potential molecular mechanism of HE, we constructed a compound-target network based on previous findings that HE contains Hericenone class compounds, Erinacine class compounds, ergosterol peroxide, cerevisterol, adenosine, and herierin III [28, 37]. We obtained a total of 182 genes from 7 gene target lists. The resulting network had 154 nodes and 190 edges (Fig. 1B). Among the genes within the network, IL (degrees of freedom $=4$ ), BCL2L1 (degrees of freedom $=3$ ), BCL2 $($ degrees of freedom $=3)$, TNF (degrees of freedom $=3$ ), CASP9 (degrees of freedom $=3$ ), PIK3CA (degrees of freedom $=3$ ), CASP3 (degrees of freedom $=3$ ), and NGF (degrees of freedom $=3$ ) were found to have the most connections with various compounds in HE, suggesting they are potential targets of HE. To establish an association between HE potential gene targets and depression, genes were retrieved from DisGeNET using the search term "Mental Depression". The results were cross-referenced with the HE gene target list to produce a protein-protein interaction network of overlapped genes (Fig. 1C), which was used in the GO and KEGG analyses.

Table 2 Phytochemical content and in vitro antioxidant activity of HE

\begin{tabular}{|c|c|c|c|c|c|}
\hline $\begin{array}{l}\text { H. erinaceus / } \\
\text { Ascorbic acid }\end{array}$ & $\begin{array}{l}\text { Total polyphenol } \\
\text { content } \\
\text { (mg GAE/g) }\end{array}$ & $\begin{array}{l}\text { Total flavonoid } \\
\text { content } \\
\text { (mg CE/g) }\end{array}$ & $\begin{array}{l}\text { Total antioxidant } \\
\text { capacity } \\
\text { (mg AAE/g) }\end{array}$ & $\begin{array}{l}\text { DPPH } \\
\left(E C_{50} ; \mathrm{mg} / \mathrm{mL}\right)\end{array}$ & $\begin{array}{l}\text { FRAP } \\
(\mu \mathrm{mol} \\
\mathrm{FeSO}_{4} \cdot 7 \mathrm{H}_{2} \mathrm{O} \\
\text { equivalents/g) }\end{array}$ \\
\hline H. erinaceus & $2.26 \pm 0.20$ & $0.73 \pm 0.03$ & $7.79 \pm 0.43$ & $1.44 \pm 0.05^{\mathrm{a}}$ & $52.34 \pm 4.82^{\mathrm{a}}$ \\
\hline Ascorbic acid & - & - & - & $0.01 \pm 0.00^{b}$ & $2648 \pm 50.29^{b}$ \\
\hline
\end{tabular}

Values are presented as mean \pm SD. Means with different letter superscripts in the same assay are significantly different $(p<0.001)$

$A A E$ ascorbic acid equivalent, $C E$ catechin equivalent, $D P P H 2,2$-diphenyl-1-picrylhydrazyl, $E C_{50}$ half-maximal effective concentration, $\mathrm{FeSO}_{4}$. $7 \mathrm{H}_{2} \mathrm{O}_{\text {ferrous sulphate, }}$ FRAP ferric reducing antioxidant power, GAE gallic acid equivalent, $H E H$. erinaceus standardised aqueous extract 


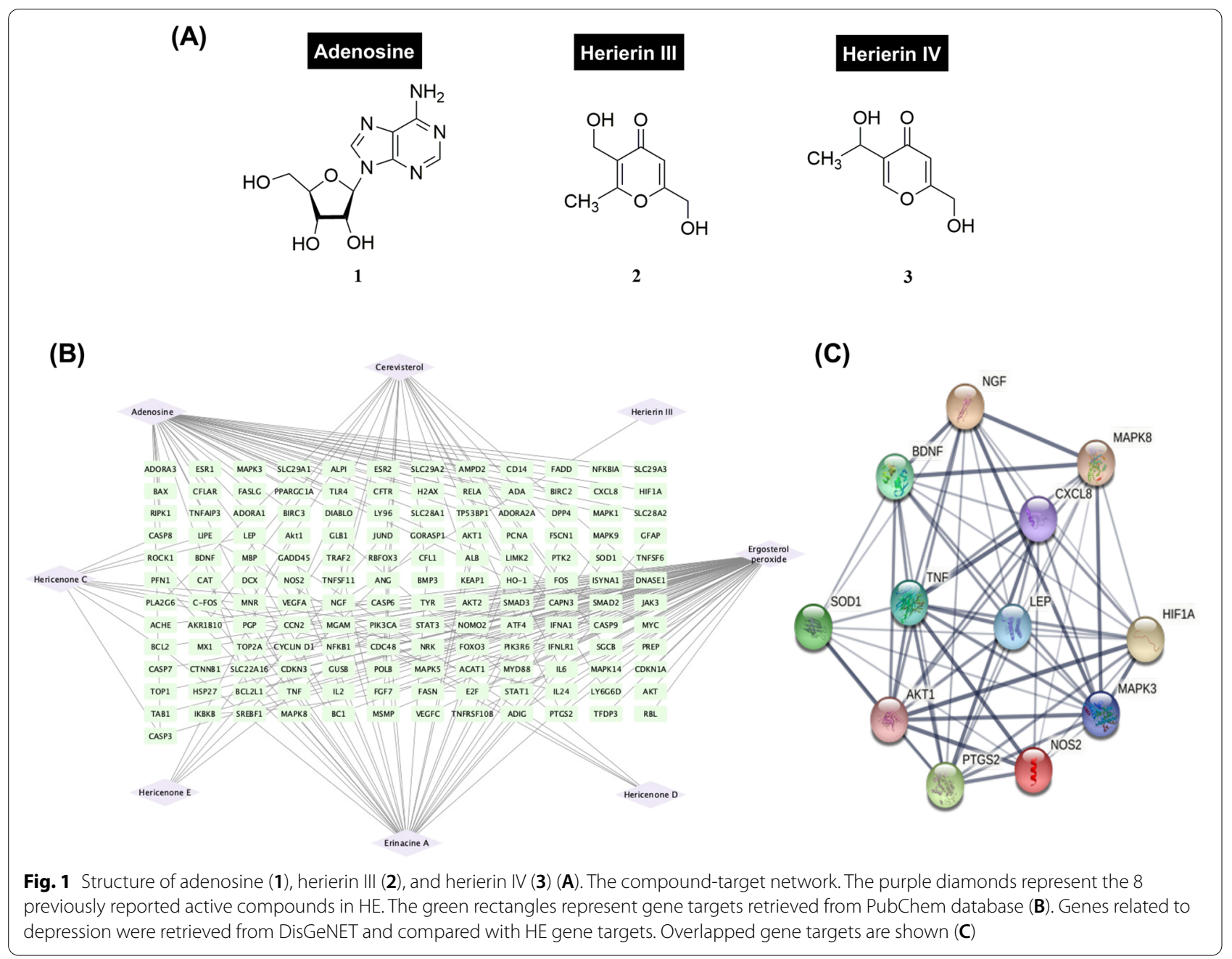

\section{GO and KEGG analyses predict the involvement of MAPK, neuroinflammation, and neurotrophin pathways in $\mathrm{HE}$-depression gene targets}

We next performed GO annotation, enrichment, and KEGG pathway analyses of HE-depression overlapped genes. The STRING database was employed to assign genes under GO terms in three categories: biological process (BP), cellular component (CC), and molecular function (MF). The results of the GO analysis returned 428 entries related to BP, 0 entries related to $\mathrm{CC}$, and 9 entries related to MF. The top 10 results with $\mathrm{p}$-value $\leq 0.01$ from each category were selectively visualized, which showed pathways under BP consisted of metabolic processes and the regulation of reactive oxygen species, whereas pathways under MF consisted of receptor-ligand activity, signalling receptor activity, and cytokine receptor binding (Fig. 2A). These results demonstrate that HE may exert its effects through the modulation of oxidative stress and molecular components involved in neuroinflammation. We then performed pathway enrichment analysis and revealed that the most significantly enriched pathways included Chagas disease, Kaposi Sarcoma-associated herpesvirus infection, IL-17 signalling pathway, AGE-RAGE signalling pathway, TNF signalling pathway, neurotrophin signalling pathway, apoptosis, and MAPK signalling pathway (Fig. 2B). Given the previously

(See figure on next page.)

Fig. 2 Bubble maps of GO annotation analysis (A) and KEGG pathway analysis (B). The $Y$ axis shows the GO terms and the names of the enriched pathways. The area of the bubble represents the number of enriched genes. Adjusted p-value represented by a colour scale, with the statistical significance increasing from blue to red (blue represents low significance and red represents high significance) 
(A)

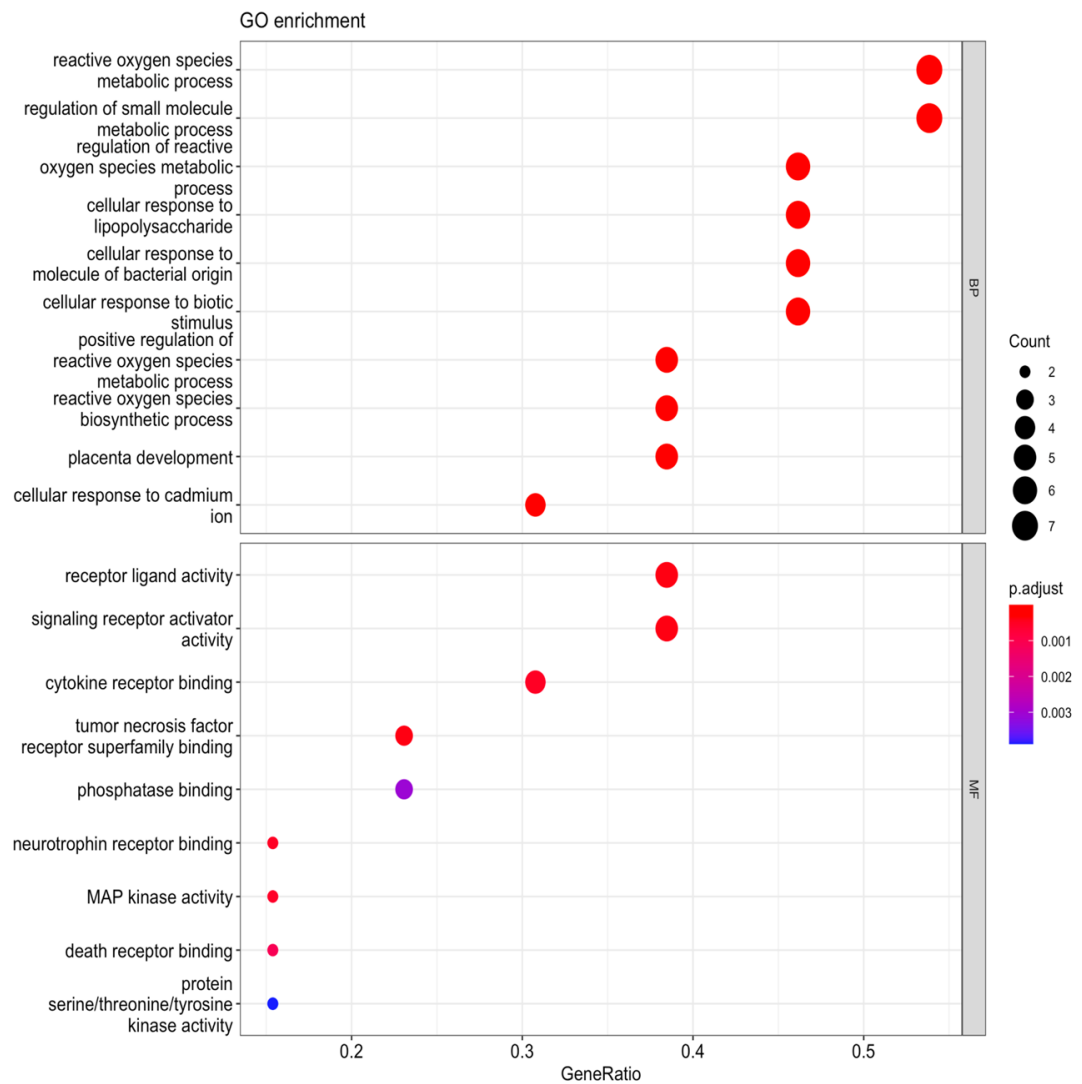

(B)

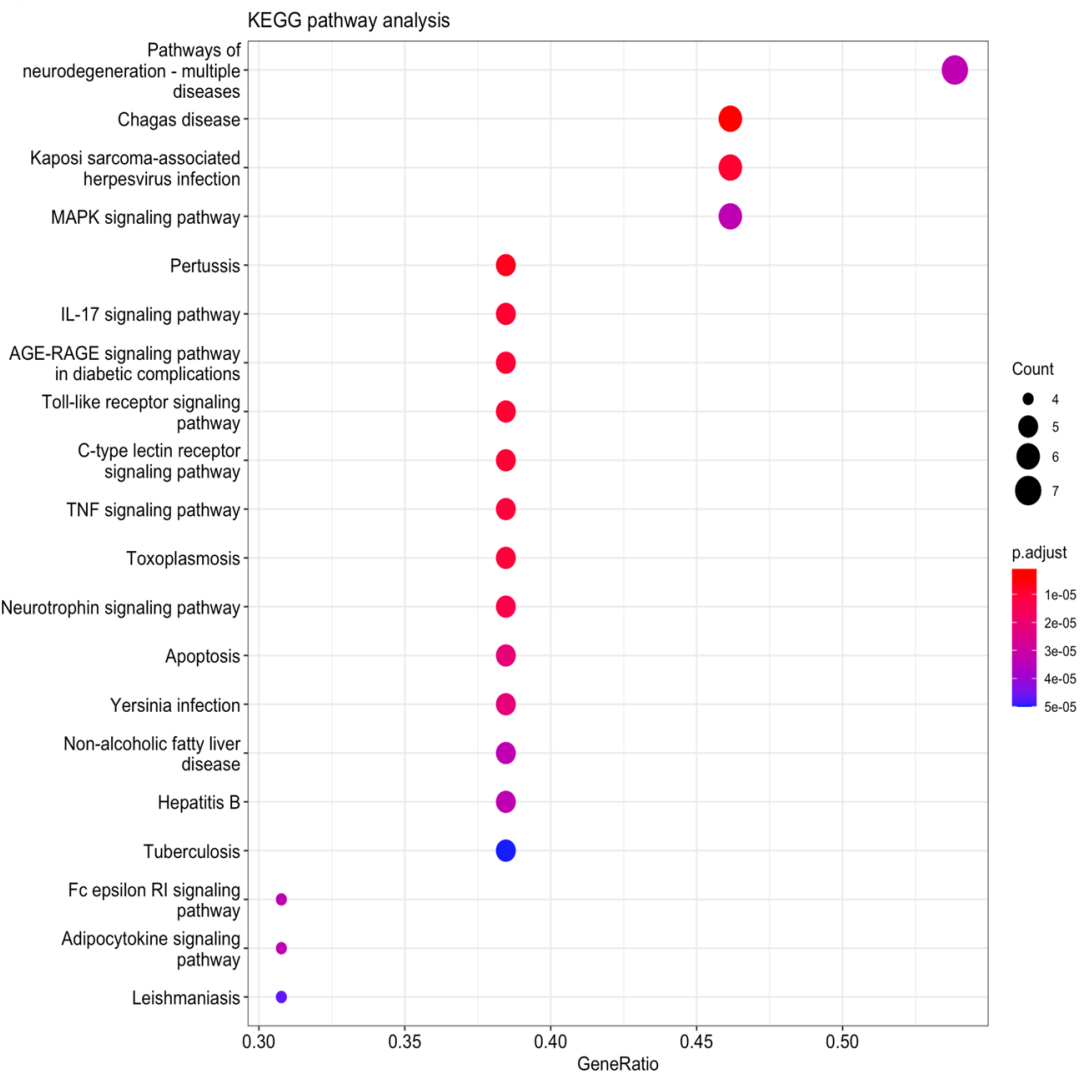

Fig. 2 (See legend on previous page.) 
reported associations of HE with MAPK signalling [50], neuroinflammation [51], and neurotrophins [52], we selected MAPK, IL-17, TNF and neurotrophin pathways for further visualization (Additional file 1: Figs. S2, S3).

\section{HE induces robust anxiolytic and antidepressant-like} effects in the animal model of depression

To demonstrate the antidepressant effect of HE in the animal model of depression, a series of behavioural tests were performed to test the animals' anxiety level and depressive-like behaviours (Fig. 3A). We first analysed the latency to emerge in the novel cage emergence test as a parameter of anxiety. One-way ANOVA revealed significant main effects on the novel cage emergence test $\left(\mathrm{F}_{(3,36)}=5.918, p=0.002\right)$ (Fig. 3B). The analysis showed no significant differences between the CRS and non-CRS control group $\left(\mathrm{t}_{(15)}=0.077, p=\right.$ n.s.). Interestingly, the CRS group treated with $25 \mathrm{mg} / \mathrm{kg} \mathrm{HE}$ exhibited significantly longer escape latency compared to the CRS + saline group $(p<0.001)$, indicating $25 \mathrm{mg} / \mathrm{kg} \mathrm{HE}$ had an anxiolytic effect. To confirm the anxiolytic property of $\mathrm{HE}$, we performed the novelty suppressed feeding test. One-way ANOVA showed significant main effects on the latency to feed among groups $\left(\mathrm{F}_{(3,38)}=5.279\right.$,
(A)

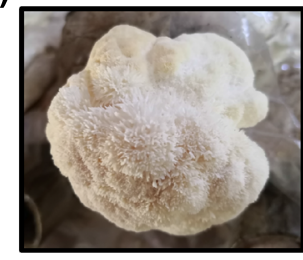
Hericium erinaceus

TMZ Injection (25 mg/kg) on Day 1, 3, 5, 8, 10, 12, 15, 17, 19, 22, 24, \& 26.

BrdU Injection (150 mg/kg) on Day 8, 10, \& 12.

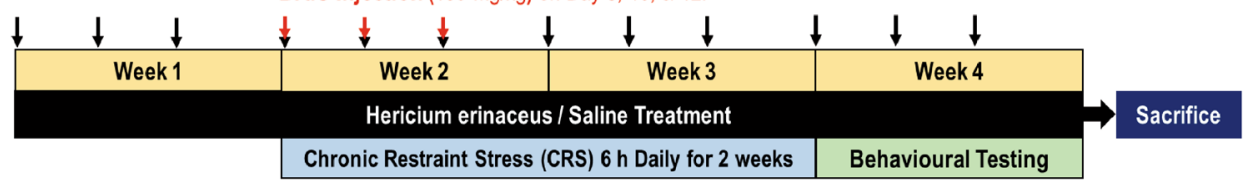

Non-TMZ or TMZ Treatments:

(1) Non-CRS + Saline

(2) CRS + Saline

(3) $\mathrm{CRS}+10 \mathrm{mg} / \mathrm{kg} \mathrm{HE}$

(4) $\mathrm{CRS}+25 \mathrm{mg} / \mathrm{kg} \mathrm{HE}$
(B)

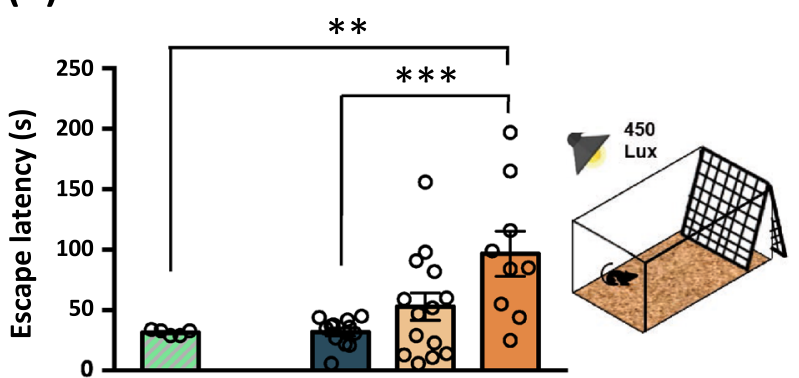

(D)
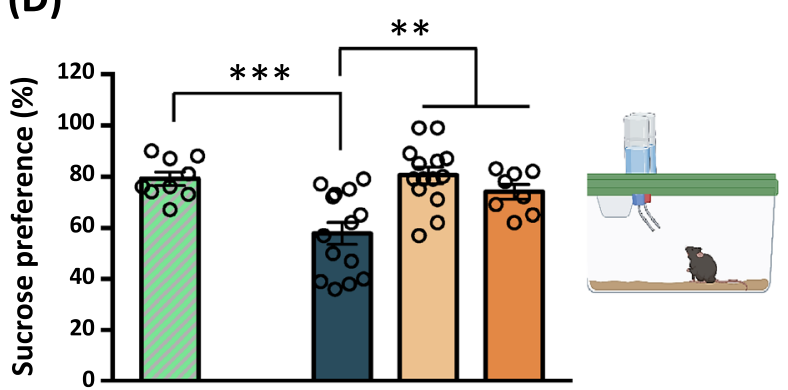

(C)

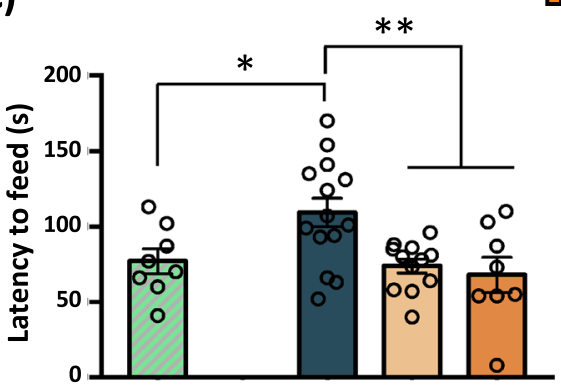

Behavioural Tests:

(1) Home-cage Emergence Test

(2) Sucrose Preference Test

(3) Novelty-Suppressed Feeding Test

(4) Tail Suspension Test

Non-CRS + Saline CRS + Saline $\square \mathrm{CRS}+10 \mathrm{mg} / \mathrm{kg} \mathrm{HE}$ CRS + $25 \mathrm{mg} / \mathrm{kg} \mathrm{HE}$

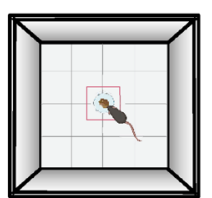

(E)

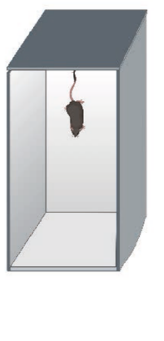

Fig. 3 Schematic representation of the study of the effects of HE in the CRS model of depression (A). The assessment of anxiety-like behaviour by escape latency in the cage emergence test (B) and by latency to feed in the novelty suppressed feeding test. $\mathbf{C}$ The evaluation of depressive-like behaviour by percentage sucrose preference $(\mathbf{D})$ and by immobility time in the tail suspension test (E). The results are presented as mean \pm S.E.M. Indicators: *Significant difference between the CRS groups. ${ }^{*} p \leq 0.05 .{ }^{* *} p \leq 0.01{ }^{* * *} p \leq 0.001$ 
$p=0.004$ ) (Fig. 3C). Validating the effect of CRS on anxiety, the Student's t-test demonstrated significant differences between the CRS + saline and non-CRS control groups $\left(\mathrm{t}_{(20)}=2.316, p=0.031\right)$. Further analysis confirmed that HE had an anxiolytic effect, as indicated by a significantly shorter latency to feed in both $10 \mathrm{mg} / \mathrm{kg}$ $\mathrm{HE}(p=0.004)$ and $25 \mathrm{mg} / \mathrm{kg} \mathrm{HE}(p=0.003)$ groups compared to the CRS + saline group. The one-way ANOVA showed similar significant group effects in the sucrose preference test $\left(\mathrm{F}_{(3,41)}=9.537, p<0.001\right)$ (Fig. 3D). The CRS + saline group exhibited lower sucrose preference as indicated by multiple comparisons compared with the non-CRS control group $\left(\mathrm{t}_{(21)}=-3.686, p=0.001\right)$. Further analysis found both $10 \mathrm{mg} / \mathrm{kg} \mathrm{HE}(p<0.001)$ and $25 \mathrm{mg} / \mathrm{kg} \mathrm{HE}(p=0.009)$ groups had a significantly higher sucrose preference level compared with the CRS + saline group. The tail suspension test was then used to assess the animals' depressive behaviour. One-way ANOVA showed significant main effects among the groups $\left(\mathrm{F}_{(3,}\right.$, 37 ) 5.023, $p=0.005$ ) (Fig. 3E). The CRS + saline group exhibited a higher degree of depressive behaviour, as indicated by a significant increase in the immobility time $\left(\mathrm{t}_{(19)}=2.515, p=0.021\right)$ compared with the non-CRS control group. Specifically, multiple comparisons showed significantly shorter immobility time in the $25 \mathrm{mg} / \mathrm{kg} \mathrm{HE}$ group ( $p=0.004$ ) compared with the CRS + saline group. These results showed that HE possesses anxiolytic and antidepressant effects, which validated the use of CRS as a viable protocol for inducing anxiety and depressive behaviours.

\section{HE administration enhances the expression of neuroplasticity-related genes}

Given the previously reported involvement of the hippocampus in the pathophysiology of depression [53], we selected the dorsal hippocampus to evaluate the expression of plasticity-related genes to identify the molecular effects of HE on depression. We found significant group effects on the gene expression of $B d n f\left(\mathrm{~F}_{(2,12)}=10.213\right.$, $p=0.003), \quad \operatorname{Trkb} \quad\left(\mathrm{F}_{(2,12)}=9.143, \quad p=0.004\right), \quad D c x$ $\left(\mathrm{F}_{(2,11)}=6.810, \quad p=0.012\right), \quad$ Syp $\quad\left(\mathrm{F}_{(2,12)}=12.227\right.$, $p=0.001)$, Nes $\left(\mathrm{F}_{(2,11)}=13.728, p=0.001\right)$, and Psd-95 $\left(\mathrm{F}_{(2,12)}=8.236, p=0.007\right)$ (Fig. $\left.4 \mathrm{~A}, \mathrm{~B}, \mathrm{D}, \mathrm{E}, \mathrm{F}, \mathrm{H}\right)$. Further analysis revealed reduced $B d n f(p=0.002)$ and $P s d-$ $95(p=0.047)$ transcript expressions in the CRS + saline group compared with the non-CRS control group, and higher gene expressions of Bdnf, Syp, Nes, and Psd-95 in both the $10 \mathrm{mg} / \mathrm{kg}$ HE group $(p=0.001 ; p<0.001$; $p<0.001 ; p=0.002$, respectively) and $25 \mathrm{mg} / \mathrm{kg} \mathrm{HE}$ group $(p=0.047 ; p=0.007 ; p=0.012 ; p=0.024$, respectively) compared with the CRS + saline group. Interestingly, the $10 \mathrm{mg} / \mathrm{kg}$ HE group showed significantly higher expressions of $D c x$ and Trkb compared with the $25 \mathrm{mg} /$ $\operatorname{kg~HE}(p=0.012 ; p=0.048)$ and CRS + saline $(p=0.007$; $p=0.001)$ groups. No significant differences were observed in transcript levels of Neun and Creb (Fig. 4C, G). These results suggest that HE possibly mediates its antidepressant effects by enhancing the expression of neuroplasticity-related genes, including restoring the $B d n f$ signalling impaired by CRS.

\section{HE increases the expression of neuroplasticity-related proteins}

To determine the molecular pathways that mediate the therapeutic effects of HE on depression, we studied changes in the activity of proteins contributing to synaptic plasticity in the dorsal hippocampus of HE-treated animals (Fig. 5A). To elucidate the molecular pathways in the neuroplasticity-related mechanisms, we first assessed the components of BDNF signalling and their involvement in the pathophysiology of depression [53]. One-way ANOVA revealed a marginally significant difference in the protein expression of $\operatorname{TrkB}\left(\mathrm{F}_{(2,13)}=3.734, p=0.052\right)$ and significant difference in pTrkB level $\left(\mathrm{F}_{(2,11)}=4.811\right.$, $p=0.032)$. Further analysis showed reductions in both $\operatorname{TrkB}(p=0.003)$ and $\operatorname{pTrkB}(p=0.007)$ protein levels in CRS + saline animals compared with non-CRS control animals (Fig. 5B, C). Compared with CRS + saline group, TrkB levels were significantly increased in the $10 \mathrm{mg} /$ $\mathrm{kg}$ HE group, but not in $25 \mathrm{mg} / \mathrm{kg}$ HE group, although both 10 and $25 \mathrm{mg} / \mathrm{kg}$ HE enhanced pTrkB levels, indicating increased activation of the TrkB receptor. Next, we examined changes in the expression of pro-BDNF and its cleavage product mature BDNF (mBDNF), which interacts with $\operatorname{TrkB}$ and contributes to neuronal survival and plasticity [54]. Although no significant difference was found in the expression of pro-BDNF, we observed a marginally significant group effect on mBDNF levels $\left(\mathrm{F}_{(2,12)}=3.807, p=0.052\right)$ (Fig. 5D, E). Consistently, we observed increased pTrkB level with higher mBDNF level in the CRS $+25 \mathrm{mg} / \mathrm{kg}$ HE group compared with the CRS + saline group. We also assessed the level of CREB and its phosphorylated form pCREB, a downstream molecule in BDNF-TrkB signalling [53]. We observed marginally significant differences in $\operatorname{CREB}\left(\mathrm{F}_{(2,13)}=3.746\right.$, $p=0.052)$ and $\mathrm{pCREB}\left(\mathrm{F}_{(2,12)}=3.854, p=0.051\right)$ protein expression levels (Fig. 5F, G). The $10 \mathrm{mg} / \mathrm{kg}$ HE group, but not $25 \mathrm{mg} / \mathrm{kg}$ HE group, showed increased CREB protein levels in the dorsal hippocampus $(p=0.021)$. Compared with non-CRS control animals, CRS + saline animals showed reduced PCREB levels $(p=0.042)$, which were effectively restored by the administration of $25 \mathrm{mg} /$ $\mathrm{kg} \mathrm{HE}(p=0.020)$. These findings suggest an impaired BDNF-TrkB-CREB signalling pathway in animals receiving CRS, which could be effectively rescued by HE. 
*

(A)

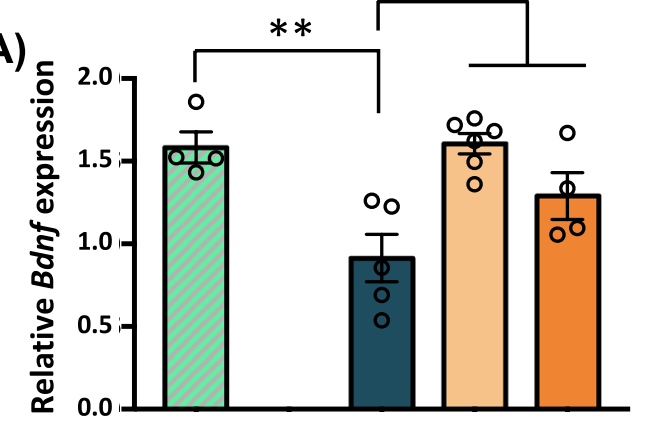

(C)

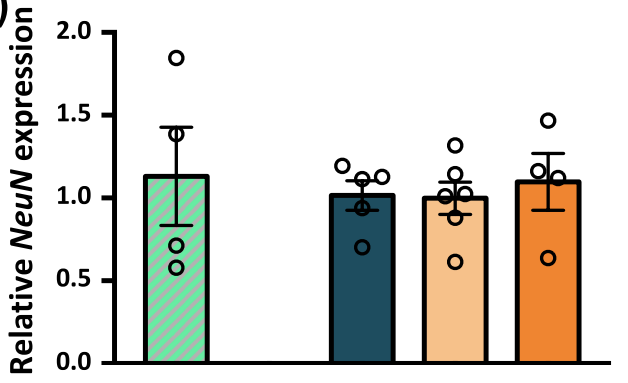

(E)

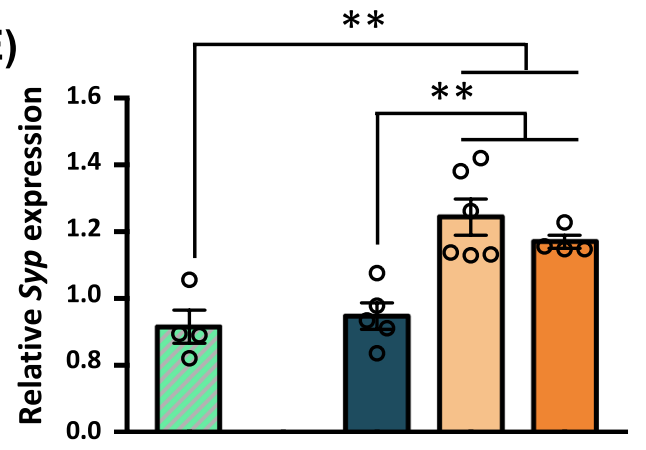

(G)

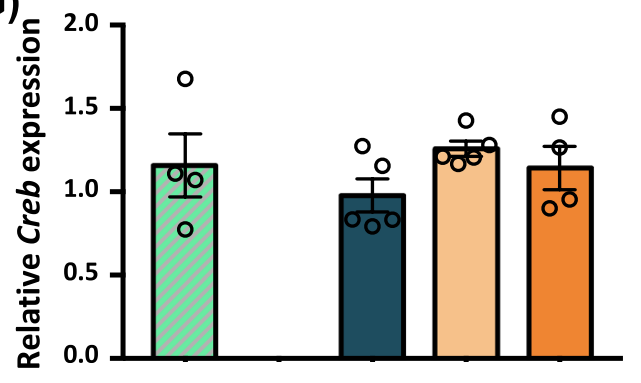

(B)

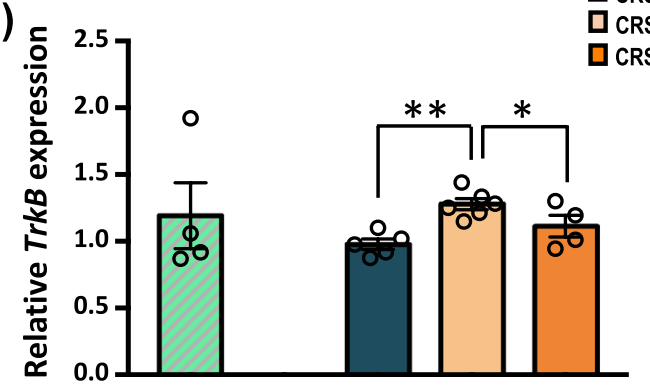

(D)

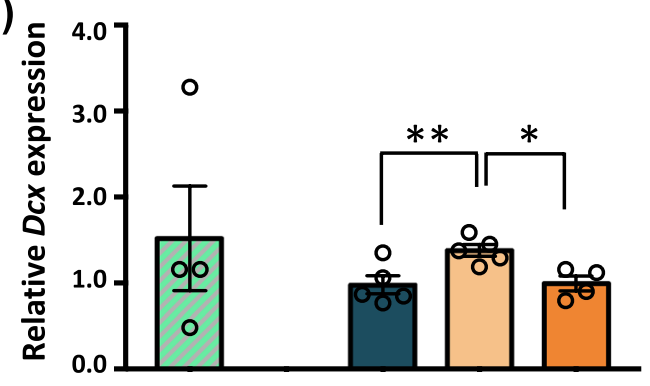

(F)

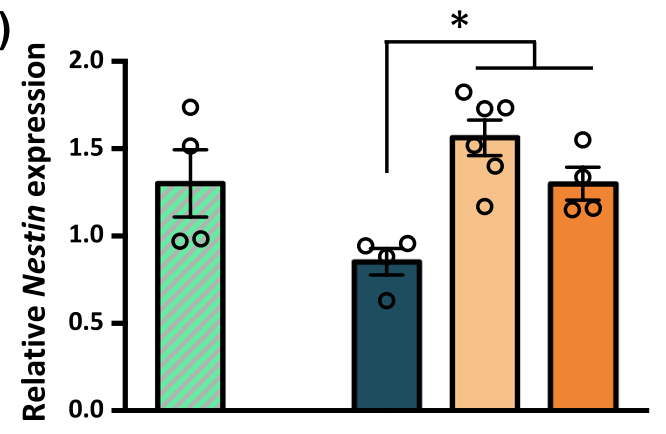

(H)

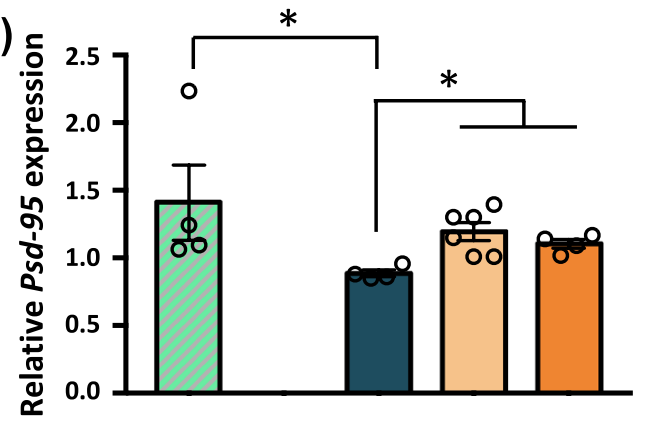

Fig. 4 Effects of HE on the relative expression of neuroplasticity- and neurogenesis-related genes including Bdnf (A), Trkb (B), NeuN (C), Dcx (D), $\operatorname{Syp}(\mathbf{E})$, Nes $(\mathbf{F})$, Creb $(\mathbf{G})$, and Psd-95 (H) in the dorsal hippocampus of non-CRS + saline, CRS + saline, CRS + $10 \mathrm{mg} / \mathrm{kg} \mathrm{HE}$ and CRS $+25 \mathrm{mg} / \mathrm{kg}$ HE groups. BDNF was significantly downregulated in the CRS + saline group. Notably, 10 and $25 \mathrm{mg} / \mathrm{kg} H E$ increased the expressions of Bdnf, Syp, Nes, and Psd-95. Relative expression was calculated by normalising the relative quantifications to the reference gene GAPDH as a ratio of the $2 \wedge C T$ (reference) and $2 \wedge C T$ (test). ${ }^{*} p \leq 0.05 .{ }^{* *} p \leq 0.01$ 


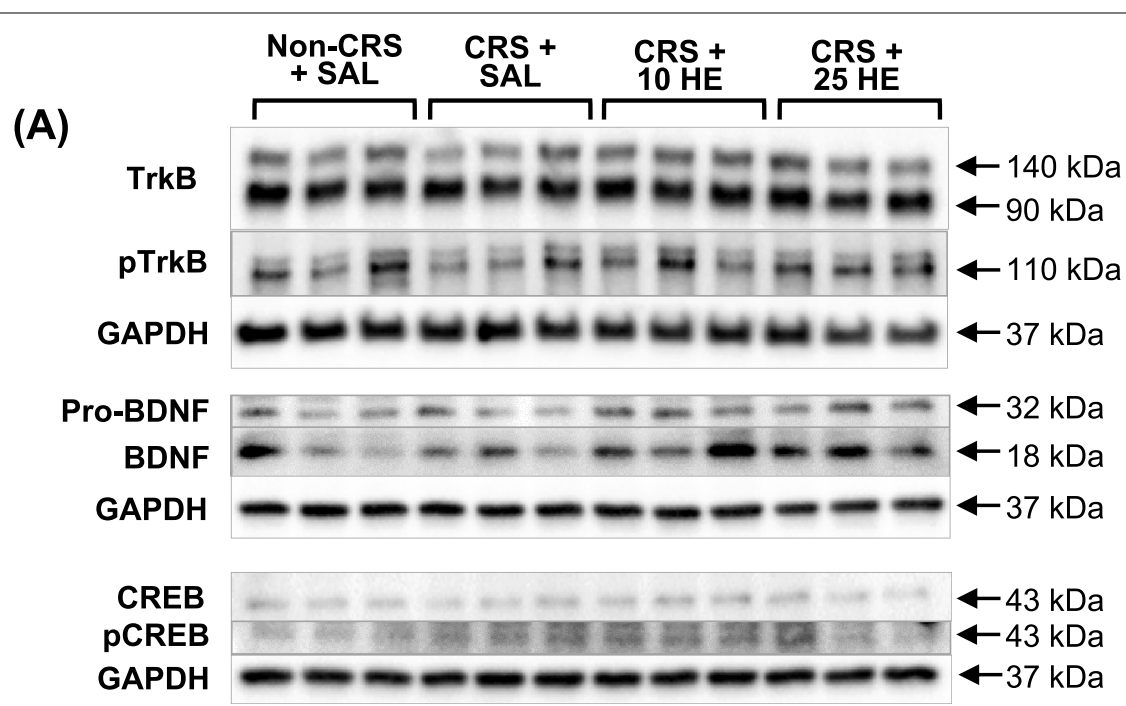

(B)

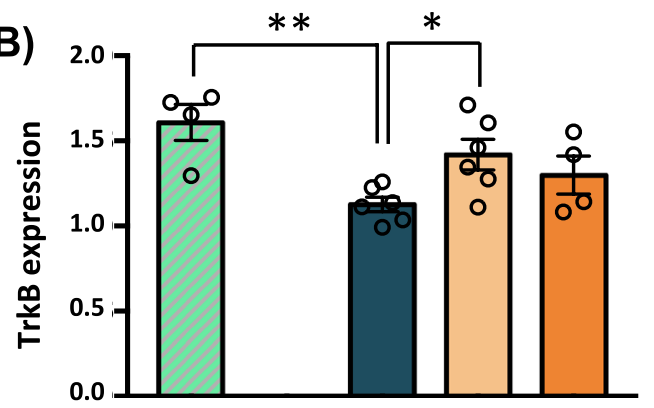

(D)

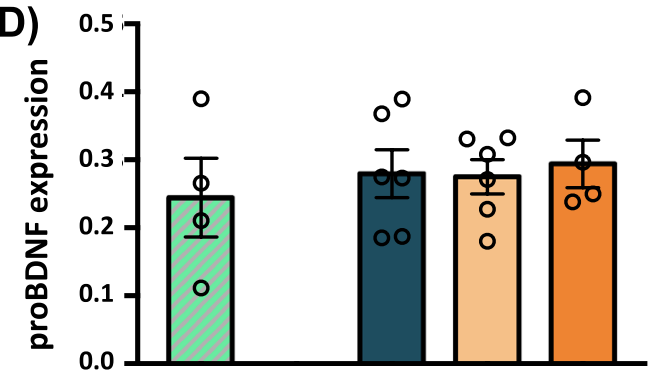

(F)

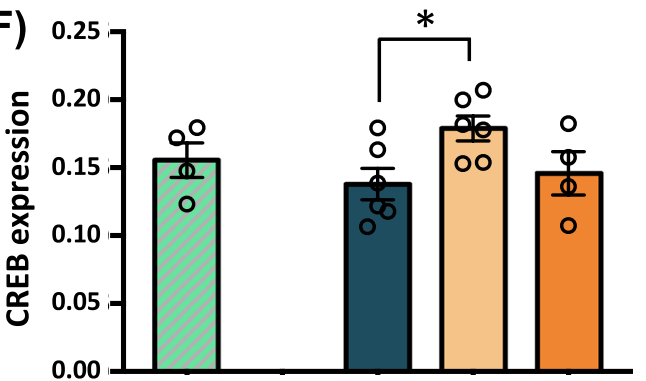

(C)

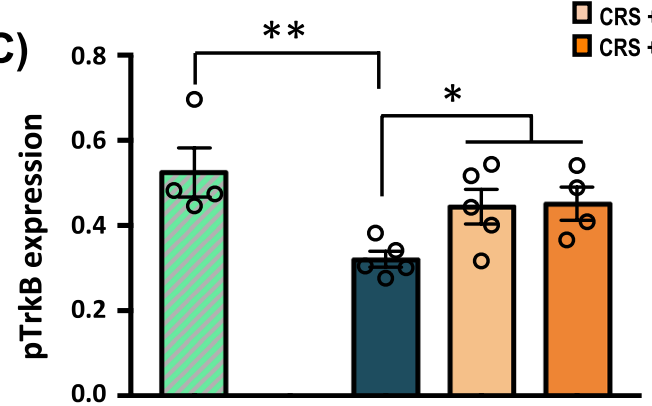

(E)

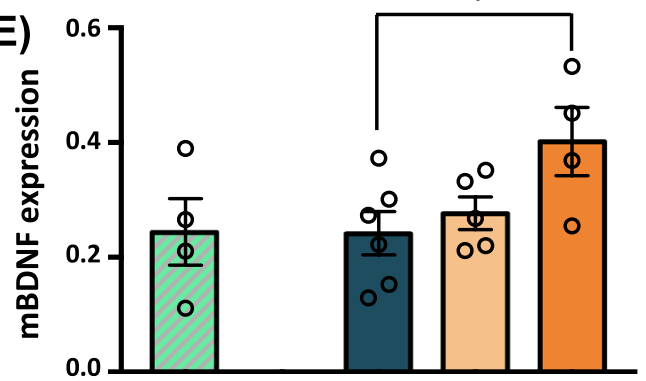

(G)

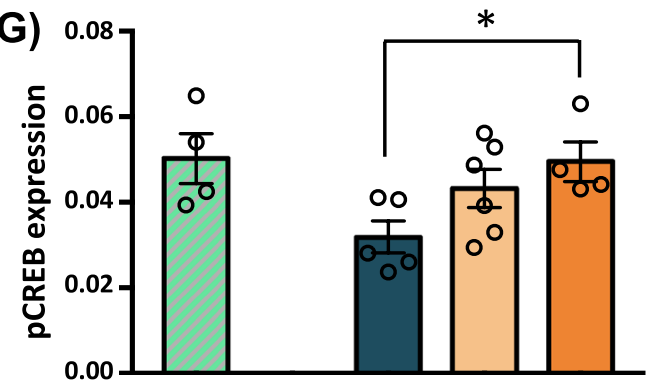

Fig. 5 Western blot analysis of proteins associated with BDNF/TrkB signalling in dorsal hippocampal tissue from non-CRS + saline, CRS + saline, CRS $+10 \mathrm{mg} / \mathrm{kg} \mathrm{HE}$, and CRS $+25 \mathrm{mg} / \mathrm{kg}$ HE groups. Note, dividing lines represent cropped blots and white spaces represent cropped bands. Graphical representation of the effects of HE on the expression of neuroplasticity-related proteins (A) including TrkB (B), pTrkB (C), pro-BDNF (D), mature BDNF $(\mathbf{E})$, CREB $(\mathbf{F})$, and PCREB $(\mathbf{G})$. The expression of target proteins was normalised to the expression of GAPDH. Note, there were significant increases in the expression of $\mathrm{pTrkB}, \mathrm{mBDNF}$, and pCREB proteins in the CRS $+25 \mathrm{mg} / \mathrm{kg}$ HE group compared with the CRS + saline group. ${ }^{*} p \leq 0.05 .{ }^{* *} p \leq 0.01$ 
Given that $25 \mathrm{mg} / \mathrm{kg} \mathrm{HE}$ was able to restore the reduced CREB phosphorylation, we examined the expression of proteins and the activation of protein kinases, including ERK1/2 [55] and AKT [56], which were previously reported to phosphorylate CREB (Fig. 6A). One-way ANOVA showed no significant difference in ERK1/2 protein level among groups $\left(\mathrm{F}_{(2,13)}=0.741, p=\right.$ n.s. $)$, indicating that CRS and HE did not affect the basal expression level of ERK1/2 (Fig. 6B). Interestingly, a significant group effect was observed on the phosphorylation of ERK1/2 $\left(\mathrm{F}_{(2,13)}=4.173, p=0.040\right)$, in which a reduced pERK1/2 level was observed in CRS + saline animals compared with non-CRS control animals $(p=0.043)$, which was effectively rescued by $10 \mathrm{mg} / \mathrm{kg} \operatorname{HE}(p=0.016)$. However, further improvement was not observed with
$25 \mathrm{mg} / \mathrm{kg} \mathrm{HE}$ (Fig. 6C). On the other hand, a significant group effect was observed in the expression of AKT $\left(\mathrm{F}_{(2,}\right.$ $\left.{ }_{13)}=4.43, p=0.034\right)$, in which both $10 \mathrm{mg} / \mathrm{kg}(p=0.037)$ and $25 \mathrm{mg} / \mathrm{kg} \mathrm{HE}(p=0.018)$ groups had reduced AKT protein levels compared with the CRS + saline group (Fig. 6D), whereas CRS increased AKT phosphorylation $(\mathrm{p}=0.047)$. However, HE did not affect AKT phosphorylation $\left(\mathrm{F}_{(2,13)}=1.65, p=\right.$ n.s.) (Fig. $\left.6 \mathrm{E}\right)$.

\section{HE promotes hippocampal neurogenesis in an animal model of depression}

Based on the results from the gene and protein assays that demonstrated enhancement in neurogenesis-related molecular pathways and the results from the behavioural screening that supported a

(A)

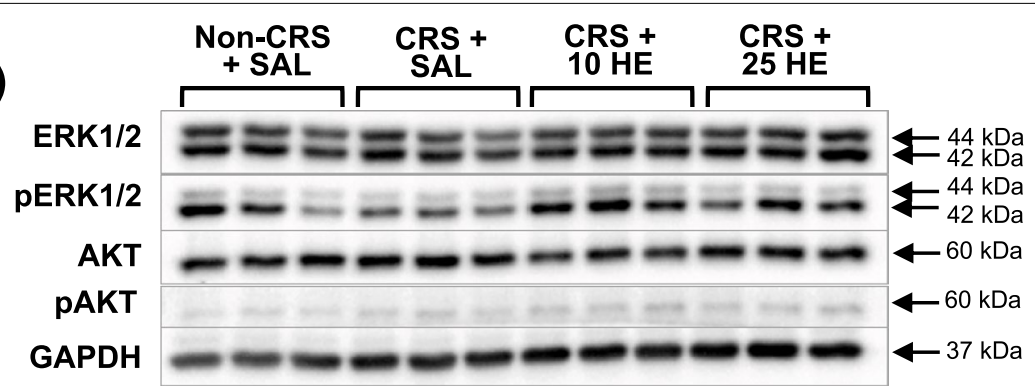

(B)

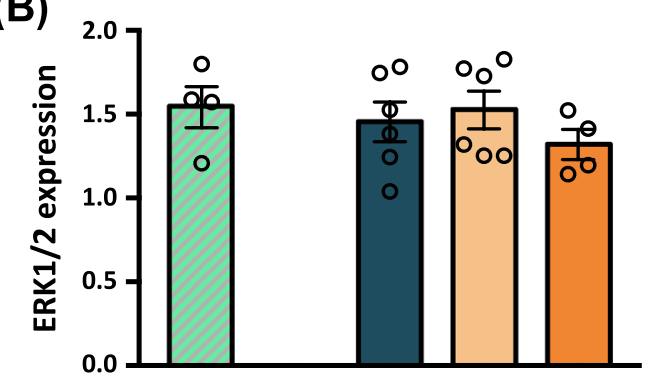

(D)

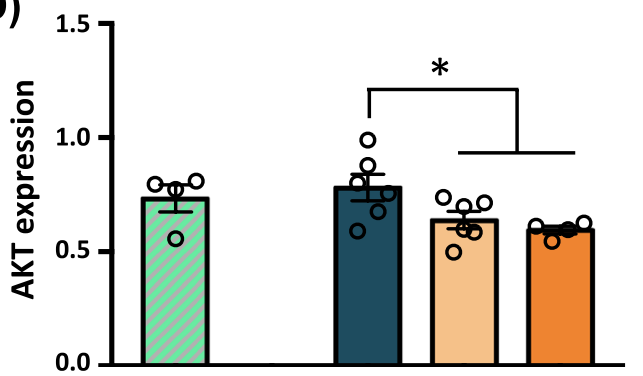

(C)$$
\text { C) }
$$

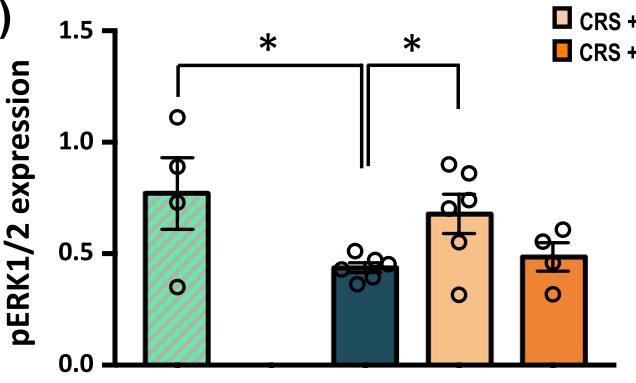

Non-CRS + Saline CRS + Saline CRS $+10 \mathrm{mg} / \mathrm{kg} \mathrm{HE}$ CRS $+25 \mathrm{mg} / \mathrm{kg} \mathrm{HE}$

(E)

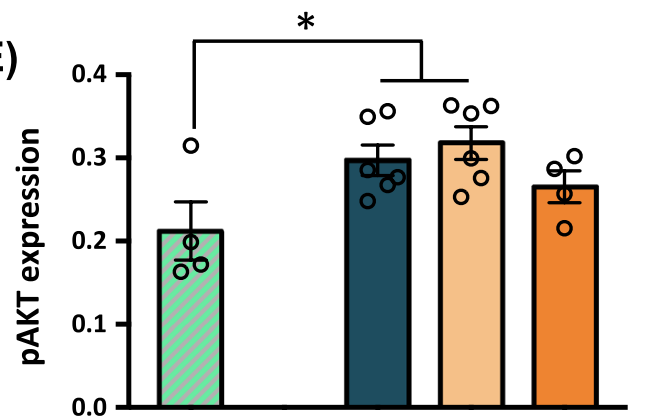

Fig. 6 Western blot analysis of proteins associated with CREB phosphorylation in dorsal hippocampal tissue from non-CRS + saline, CRS + saline, CRS $+10 \mathrm{mg} / \mathrm{kg} \mathrm{HE}$, and CRS $+25 \mathrm{mg} / \mathrm{kg}$ HE groups. Note, dividing lines represent cropped blots and white spaces represent cropped bands. Blot images $(\mathbf{A})$ and graphical representation of the effects of HE on the expression of neuroplasticity-related proteins including ERK1/2 (B), pERK1/2 (C), AKT (D), and pAKT (E). The expression of target proteins was normalised to the expression of GAPDH. Note, in CRS $+10 \mathrm{mg} / \mathrm{kg} \mathrm{HE} \mathrm{group,} \mathrm{there} \mathrm{was}$ a significant increase in pERK $1 / 2$ protein expression compared with the CRS + saline group and increase in pAKT compared to the non-CRS control group. ${ }^{*} p \leq 0.05$ 
neurogenesis-dependent mechanism of the antidepressant-like effects of $\mathrm{HE}$, we performed further morphological studies on the dentate gyrus (DG) of the hippocampus, a region where adult neurogenesis mainly occurs [57] (Fig. 7A). Quantification of neurogenesis marker $\mathrm{BrdU}^{+}$cells in the DG revealed a significant group effect $\left(\mathrm{F}_{(2,170)}=23.11, p<0.001\right)$. Further analysis showed $10 \mathrm{mg} / \mathrm{kg} \mathrm{HE}$, but not $25 \mathrm{mg} / \mathrm{kg} \mathrm{HE}$, had a remarkable neurogenic effect (Fig. 7B). To determine the effect of HE treatment on neural differentiation, we examined the co-localisation of BrdU with mature neuronal marker NeuN in the DG. One-way ANOVA on CRS animals showed a significant group effect in the DG $\left(\mathrm{F}_{(2,160)}=4.95, p=0.008\right)$. Interestingly, animals receiving $25 \mathrm{mg} / \mathrm{kg} \mathrm{HE}$ had significantly lower $\mathrm{BrdU}^{+} / \mathrm{NeuN}^{+}$cell count in the DG (Fig. 7C). Taken together, these results provide morphological evidence supporting that $10 \mathrm{mg} / \mathrm{kg} \mathrm{HE}$ has higher efficacy in promoting hippocampal neurogenesis.

\section{Blockade of neurogenesis abolishes the anxiolytic and antidepressant-like effects of HE in an animal model of depression}

In view of the observed molecular mechanisms underlying the antidepressant-like effects of $\mathrm{HE}$, we next evaluated if neurogenesis mediated the effects of $\mathrm{HE}$ on depression. Animals subjected to the CRS protocol were administered a neurogenesis blocker TMZ together with HE treatments before being subjected to behavioural testing. Although no significant difference was observed in cage emergence test $\left(\mathrm{F}_{(2,19)}=0.929, \mathrm{p}=\right.$ n.s. $)$ (Fig. $\left.8 \mathrm{~A}\right)$, the
(A)

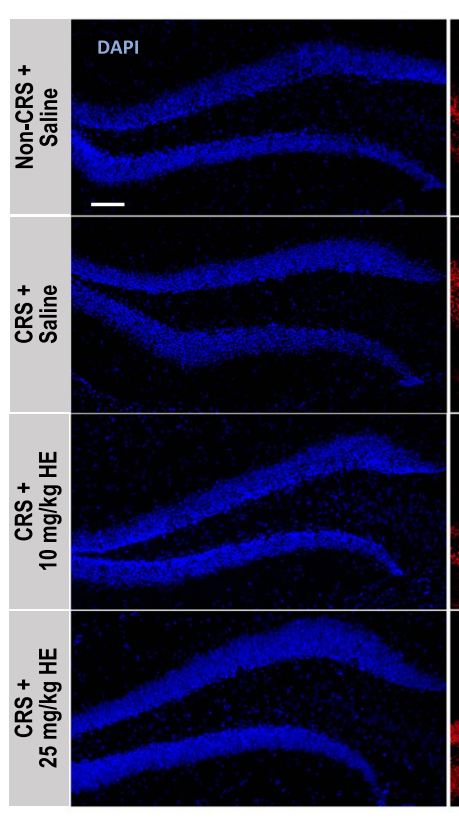

(B)

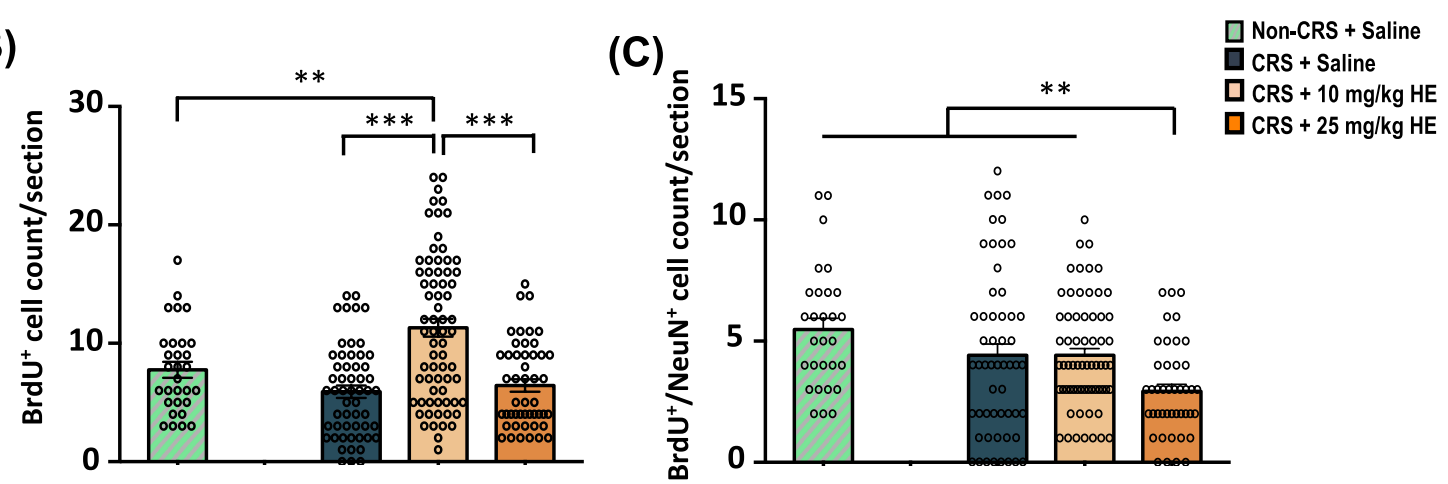

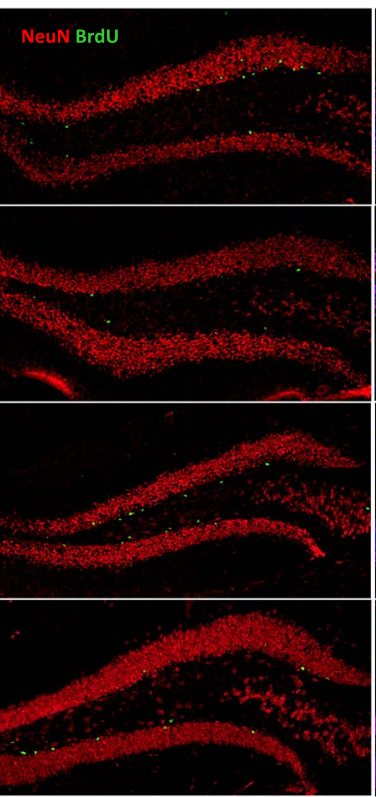

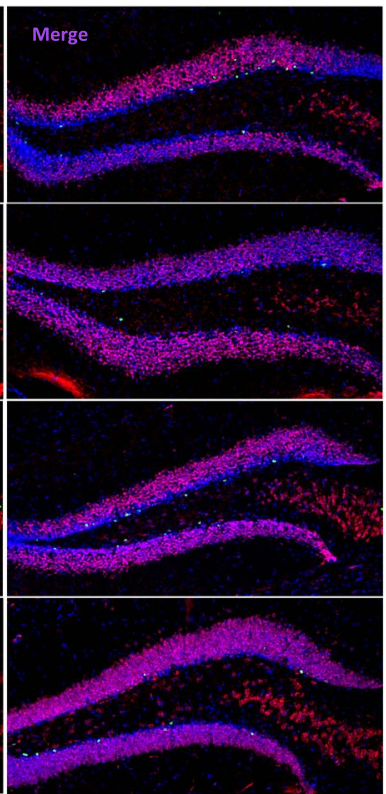

Fig. 7 Immunofluorescence staining of BrdU and NeuN in the DG reveals a dosage-dependent effect of HE treatment on neurogenesis. Scale bar: $100 \mu \mathrm{m}(\mathbf{A})$. Note, there was a significant increase in BrdU ${ }^{+}$cells in the DG of CRS animals receiving $10 \mathrm{mg} / \mathrm{kg} \mathrm{HE}, \mathrm{but}$ not $25 \mathrm{mg} / \mathrm{kg} \mathrm{HE}(\mathbf{B})$. Double

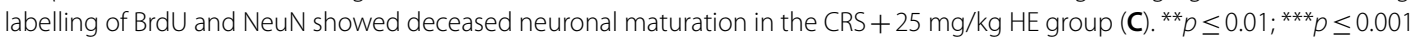




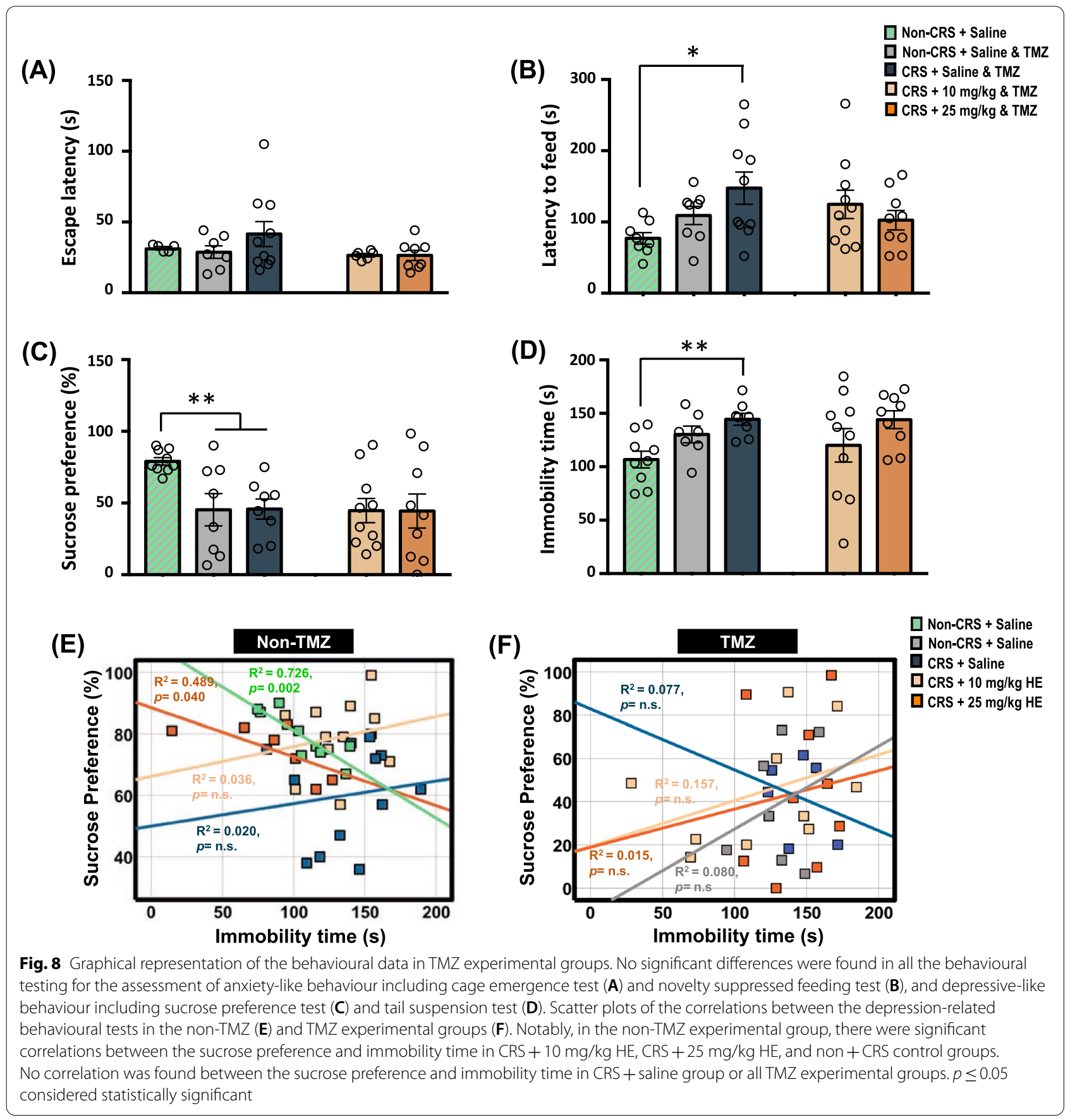

one-way ANOVA of the saline-treated groups revealed significant group effect in novelty suppressed feeding test $\left(\mathrm{F}_{(2,23)}=4.38, \mathrm{p}=0.024\right)$ (Fig. $\left.8 \mathrm{~B}\right)$, sucrose preference test $\left(\mathrm{F}_{(2,22)}=6.90, \mathrm{p}=0.005\right)$ (Fig. $\left.8 \mathrm{C}\right)$, and tail suspension test $\left(\mathrm{F}_{(2,21)}=7.41, \mathrm{p}=0.004\right)$ (Fig. $\left.8 \mathrm{D}\right)$. Further analysis verified the effects of TMZ administration as TMZ-treated CRS + Saline group, which exhibited a significantly higher degree of depressive behaviours, as indicated by a longer latency to feed in novelty suppressed feeding test and longer immobility time in the tail suspension test. Our results also showed that TMZ completely abolished the anxiolytic and antidepressant-like effects of HE. One-way ANOVA showed that there were no statistically significant differences between all the TMZ groups as determined by the behavioural tests, including cage emergence test $\left(\mathrm{F}_{(3,27)}=1.51, p=\right.$ n.s. $)$, novelty suppressed feeding 
test $\left(\mathrm{F}_{(3,33)}=1.20, p=\right.$ n.s. $)$, sucrose preference test $\left(\mathrm{F}_{(3,}\right.$ $\left.{ }_{31}\right)=0.004, p=$ n.s. $)$, and tail suspension test $\left(\mathrm{F}_{(3,30)}=1.22\right.$, $p=$ n.s.). These findings suggest that neurogenesis may be a plausible mechanism by which HE exerts anxiolytic and antidepressant effects. Next, we further analysed the correlation of the behavioural parameters to study the effects of neurogenesis blockade. In the non-TMZ experimental group, Pearson correlation analysis showed significant correlations between the sucrose preference percentage and immobility time in the tail suspension test in CRS $+25 \mathrm{mg} / \mathrm{kg}$ HE group $\left(\mathrm{r}^{2}=0.489, p=0.040\right)$ and the non-CRS control group $\left(\mathrm{r}^{2}=0.726, p=0.002\right)$, indicating $25 \mathrm{mg} / \mathrm{kg}$ HE potentially rescues behavioural despair due to CRS compared with normal non-CRS control animals (Fig. 8E; Table 2). No correlation was found between the sucrose preference percentage and immobility time in CRS $+10 \mathrm{mg} / \mathrm{kg}$ HE group $\left(\mathrm{r}^{2}=0.036, p=\right.$ n.s. $)$ and CRS + saline group $\left(\mathrm{r}^{2}=0.020, p=\right.$ n.s. $)$, suggesting a higher dose of HE is required to rescue behavioural despair induced by CRS. As expected, no significant correlation was found between the behavioural data in all TMZ experimental groups (all $\mathrm{r}^{2}<0.157 p=$ n.s.) (Fig. 8F), indicating the blockade of neurogenesis by TMZ disrupts the anxiolytic and antidepressant-like effects of $\mathrm{HE}$.

\section{HE reduces neuroinflammation \\ via a neurogenesis-dependent mechanism in the animal model of depression}

Activation of astrocytes and subsequently increased levels of inflammatory cytokines are commonly observed in depressed patients and preclinical animal models of depression [58-60]. To examine whether CRS induces microgliosis or astrogliosis in CRS animals, and if so, whether HE exerts antidepressant effect via neuroinflammation-dependent pathways, brain sections were stained with glial fibrillary acidic protein (GFAP). Oneway ANOVA of GFAP expression revealed significant group effects for CA1 $\left(\mathrm{F}_{(2,191)}=25.746, p<0.001\right)$, CA3 $\left(\mathrm{F}_{(2,191)}=45.184, p<0.001\right)$, and DG $\left(\mathrm{F}_{(2,191)}=16.622\right.$, $\mathrm{p}<0.001)$ in the dorsal hippocampus of animals in nonTMZ group. Multiple comparisons showed that GFAP expression was increased in the CA1 and DG of the CRS + saline group compared with the non-CRS control group. Both $10 \mathrm{mg} / \mathrm{kg}$ (all subregions: $p<0.001$ ) and $25 \mathrm{mg} / \mathrm{kg} \mathrm{HE}$ (all subregions: $p<0.001$ ) groups exhibited reduced numbers of $\mathrm{GFAP}^{+}$cells in all subregions of the dorsal hippocampus compared with the CRS + saline group. In particular, $10 \mathrm{mg} / \mathrm{kg} \mathrm{HE}$ induced a stronger GFAP reduction in the CA3 compared with $25 \mathrm{mg} / \mathrm{kg} \mathrm{HE}$ (Fig. 9A-D). The TMZ treatment in CRS + saline animals resulted in lower $\mathrm{GFAP}^{+}$cell count compared with nonCRS control animals. Moreover, significant group effects were observed in CA1 $\left(\mathrm{F}_{(2,216)}=3.54, p=0.031\right)$ and DG $\left(\mathrm{F}_{(2,211)}=12.46, p<0.001\right)$, but not in CA3 $\left(\mathrm{F}_{(2,216)}=1.97\right.$, $p=$ n.s.). Multiple comparisons revealed that TMZ could effectively abolish the influence of $10 \mathrm{mg} / \mathrm{kg} \mathrm{HE}$, but not $25 \mathrm{mg} / \mathrm{kg} \mathrm{HE}$, on hippocampal GFAP expression, as indicated by increased $\mathrm{GFAP}^{+}$cell count in the CA1 and DG of $25 \mathrm{mg} / \mathrm{kg}$ HE group (Fig. 9E-H). Taken together, these data suggest that the anti-neuroinflammatory activity of HE may be mediated by a neurogenesis mechanism.

\section{Discussion}

Hericium erinaceus is a well-known medicinal mushroom that possesses potent antioxidant properties. Endogenous and exogenous antioxidants and other phytochemicals can act to maintain or re-establish redox homeostasis in response to oxidative damage [37, 61]. Our findings showed that the total polyphenol content in $\mathrm{HE}$ was 2.1- and 1.5-fold lower than in the aqueous extract of $\mathrm{HE}$ originating from Korea (4.75 mg GAE/g) and China (3.33 mg GAE/g), respectively [62]. On the other hand, the total flavonoid content in HE was 2.1-fold higher than in the HE aqueous extract $(0.34 \pm 0.01 \mathrm{mg}$ $\mathrm{CE} / \mathrm{g}$ ) reported by Kim et al. (2013) [63], and 3.7-fold higher than in the HE aqueous extract grown on germinated green rice (HEGR-W) $(0.197 \pm 0.004 \mathrm{mg} \mathrm{CE} / \mathrm{g})$ reported by Lee et al. (2017) [64].

Yildiz et al. (2015) demonstrated that a high phenolic content contributes to potent antioxidant activities in numerous medicinal mushrooms including HE [65]. We found the total antioxidant capacity of HE was 1.5-fold lower than in the HE aqueous extract (11.93 mg AAE/g) reported by Charumathy et al. (2016) [66]. Nevertheless, our results also demonstrated that HE had higher DPPH free radical scavenging activity, with a 1.5-fold lower $\mathrm{EC}_{50}$ value compared to that in the hot water extract of $\mathrm{HE}(2.13 \mathrm{mg} / \mathrm{mL})$ from fresh fruiting bodies [66]. $\mathrm{Li}$ et al. (2012) showed a water subfraction of HE methanol extract had an $\mathrm{EC}_{50}$ value of $4.8 \mathrm{mg} / \mathrm{mL}$, which was 3.3-fold higher than in HE [67]. This is in agreement with HE water and ethanol extracts reported by Jiang et al. (2016), which exhibited the highest antioxidant activities among other solvent extracts, indicating the antioxidant activity was attributed to the polar ingredients [68]. Our results also demonstrated the FRAP value of HE was 2.7fold higher than in a water subfraction from a methanol extract $\left(19.46 \pm 1.05 \mu\right.$ mol $\mathrm{FeSO}_{4} .7 \mathrm{H}_{2} \mathrm{O}$ equivalents/g) of fresh HE fruiting bodies reported by $\mathrm{Li}$ et al. (2012) [67]. The FRAP value of HE was 5.5-fold higher than in an acetone/water/acetic acid (ratio of 70:29.5:0.5) extract $\left(9.6 \pm 0.6 \mu \mathrm{mol} \mathrm{FeSO}_{4} .7 \mathrm{H}_{2} \mathrm{O}\right.$ equivalent/g) from $\mathrm{HE}$ fruiting bodies [69]. This finding was in agreement with water 
(A)

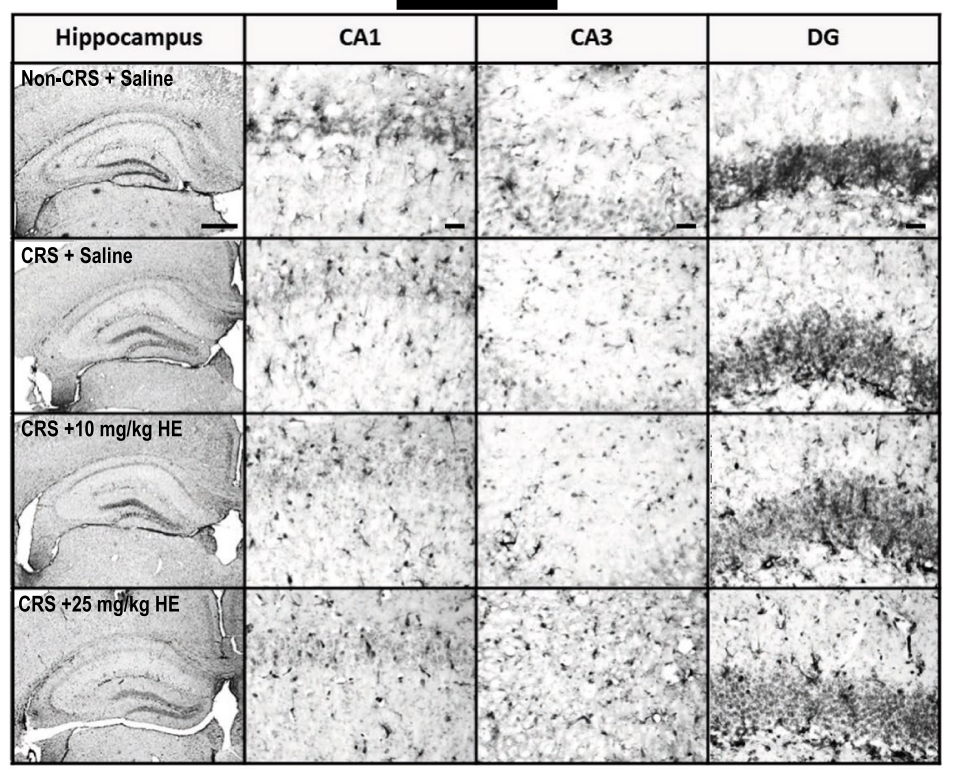

(B)

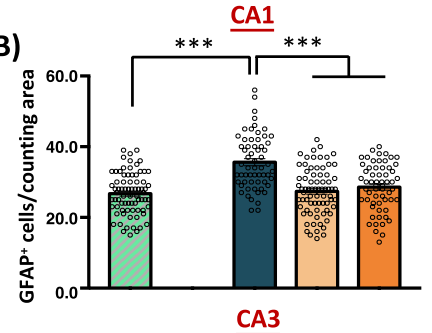

(C)

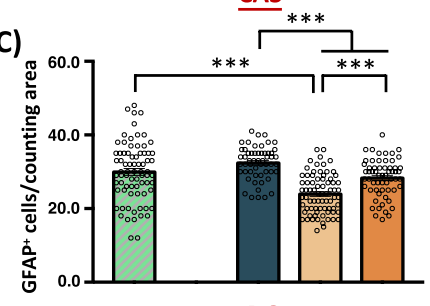

(D)

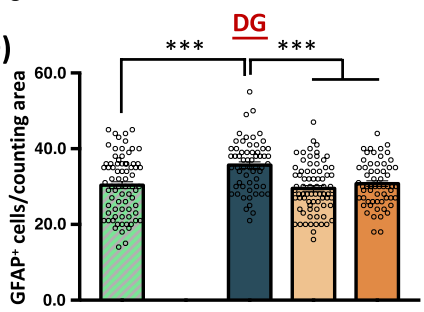

(F)

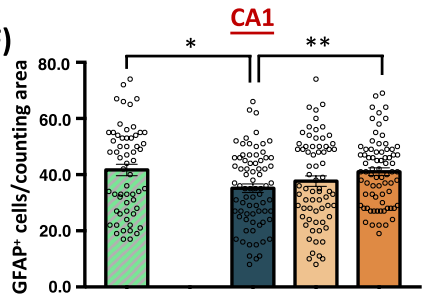

(G)

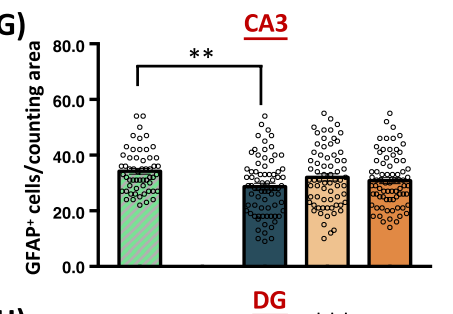

$(\mathrm{H})$

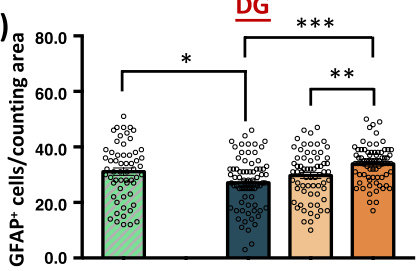

Fig. 9 Immunohistochemical analysis of GFAP (astrocyte marker) in the hippocampus of non-CRS + saline, CRS + saline, CRS + $10 \mathrm{mg} / \mathrm{kg} \mathrm{HE}$, and CRS $+25 \mathrm{mg} / \mathrm{kg} \mathrm{HE}$ group. Scale bar: $200 \mu \mathrm{m}$ (hippocampus) and $50 \mu \mathrm{m}$ (subregions) (A). The degree of astrocyte activation was examined in the CA1 (B), CA3 (C), and DG (D), separately. Notably, the CRS + saline group exhibited increased astrocyte activation in the CA1 and DG, which was suppressed by 10 and $25 \mathrm{mg} / \mathrm{kg} \mathrm{HE}$. To probe whether the observed suppression was mediated by hippocampal neurogenesis, the hippocampus of TMZ-treated animals was stained with GFAP in the same subregions. TMZ administration abolished the suppressive effects of HE (E-H) 
and hot water extracts that possessed higher antioxidant properties than acetone and ethanol extracts [70].

Our previous findings showed that HE consists of two major compounds, namely adenosine and herierin III. Adenosine was isolated as a white powder with a molecular formula of $\mathrm{C}_{10} \mathrm{H}_{13} \mathrm{~N}_{5} \mathrm{O}_{4}$. It is an endogenous nucleoside classified under glycosylamines with an adenine attached to a ribose. Herierin III was isolated as a colourless oil with a molecular formula of $\mathrm{C}_{8} \mathrm{H}_{10} \mathrm{O}_{4}$. It is a heterocyclic compound classified under pyrones [37].

Herierin IV was first discovered by Qian et al. [71] from HE mycelia cultivated on solid media. The yield of herierin IV was $0.005 \%$, which is 0.022 -fold lower than the amount $(0.227 \%)$ obtained from ethyl acetate extract of HE mycelia [72]. The yield was also found to be 0.25 -fold lower than the amount (0.02\%) from methanol extract of HE mycelia [73]. Herierin IV is a heterocyclic aromatic compound classified as a pyrone. The health promoting effects of this compound have not been previously reported [74].

In a recent study by Chiu et al. (2018), an ethanol extract of erinacine A enriched-HE mycelium was found to revert the depression-like behaviour via the activation of BDNF/TrkB/PI3K/Akt/GSK-3 $\beta$ pathways and inhibition of NF- $\mathrm{KB}$ signalling in mice challenged by repeated restraint stress [23]. In addition, our study suggests a contributory role of neurogenesis in the amelioration of depressive-like behaviours using an established TMZtreatment protocol. Hippocampal neurogenesis was pharmacologically blocked with TMZ. Furthermore, HE used in this study is a trademark registered with the Intellectual Property Corporation of Malaysia (No. 2018001586) and is classified as a dietary supplement for humans. The antidepressant effects have been attributed to the major compounds found in HE, namely adenosine, herierin III, and herierin IV.

In the current study, we used the network pharmacology approach to predict the potential genes and pathways by which HE mediates its effects. We performed GO enrichment and KEGG pathway analyses, which showed that activity of HE compounds were associated with various neurochemical processes that are dysregulated in depression, including MAPK, IL-17, TNF and neurotrophin signalling. This observation may have profound implications. MAPK is consistently reported to be an essential molecule in the pathophysiology of depression. Interestingly, Duric et al. [75] demonstrated that MAPK cascade inhibition by upregulating MAPK phosphatase (MKP-1) expression was sufficient to induce depressive-like behaviours in rodents. This finding was further confirmed in post-mortem samples, where augmented MKP-1 expression was detected in the hippocampus of a depressed subject [75]. On the other hand, elevated peripheral IL and TNF levels were reported in patients with depression [76]. Accumulating data suggests that specific classes of antidepressants indeed normalize dysregulated pro-inflammatory cytokines in depression [77], possibly validating the inflammatory hypothesis of depression, which could be targeted in the development of antidepressants. Neurotrophic factors such as BDNF and NGF have also attracted attention in terms of their potential as antidepressants $[53,78]$. To further illustrate the complexity of the molecular pathology of depression, MAPK signalling also serves as an intermediate component downstream of the BDNF-TrkB cascade. These findings, together with the results from GO and KEGG pathway enrichment analyses, show that the aforementioned pathways are tightly linked with the pathological mechanism of depression.

Common symptoms of clinical depressive disorders include anxiety, low mood, decreased appetite, lack of motivation, anhedonia, tiredness, and hopelessness [2, 3]. The CRS animal model of depression generated robust depressive-like behavioural phenotypes. After 2 weeks of $6 \mathrm{~h}$ consecutive restraint stress, animals with CRS exhibited early latency to escape from the aversive cage and higher latency to feed in the brightly lit open field compared with non-CRS control animals, indicating increased levels of anxiety. Furthermore, the CRS + saline group showed significantly reduced sucrose intake and increased immobility time in the tail suspension test compared with the non-CRS control group, suggesting anhedonia and behavioural despair induced by CRS. The anxiety and depression-related behavioural results showed marked differences between the behavioural phenotypes of the non-CRS control and CRS + saline groups, validating the CRS-induced animal model of depression.

The results revealed that CRS animals receiving the $25 \mathrm{mg} / \mathrm{kg}$ HE treatment had longer latency of escape from the aversive cage compared with CRS + saline animals, suggesting $25 \mathrm{mg} / \mathrm{kg} \mathrm{HE}$ has potential anxiolytic effects. In the novelty suppressed feeding test, CRS groups receiving 10 or $25 \mathrm{mg} / \mathrm{kg}$ HE treatments had shorter latency to feed compared with the CRS + saline group, suggesting both HE treatment dosages improved anxiety and motivation for food intake. Additionally, significantly higher sucrose consumption was demonstrated in both HE treatment groups compared with the $\mathrm{CRS}+$ saline group, indicating HE has anti-anhedonic effects. The CRS animals receiving $25 \mathrm{mg} / \mathrm{kg} \mathrm{HE}$ exhibited a lower immobility time in the tail suspension test, indicating $25 \mathrm{mg} / \mathrm{kg} \mathrm{HE}$ could rescue behavioural despair in the CRS animals. Overall, the behavioural findings demonstrated that HE can ameliorate depressive-like behaviours in the CRS animal model of depression. 
Previous findings showed that depression was associated with neuronal atrophy and loss of neurones, especially in the hippocampus [79]. In this study, we focused on the neurogenesis-related changes in the dorsal hippocampus involved in the antidepressant-like effects of HE. Gene assay results revealed that $B d n f$ transcript level in the dorsal hippocampus was significantly lower in the CRS + saline group compared with the non-CRS control group, which is consistent with previous reports that demonstrated an association between decreased BDNF expression and depressive-like symptoms [80, 81]. The hypothesis that BDNF replenishment mediates antidepressant effects supports the role of BDNF in depressive disorders, as BDNF was found to possibly play a role in the therapeutic mechanism of antidepressants [80, 82]. We found both the CRS $+10 \mathrm{mg} / \mathrm{kg} \mathrm{HE}$ and CRS $+25 \mathrm{mg} / \mathrm{kg}$ HE treatment groups exhibited significantly increased neuroplasticity- and neurogenesisrelated gene expressions, including Bdnf, Syp, Nestin, and Psd-95. Interestingly, gene expressions of TrkB and $D c x$ were significantly elevated in the $10 \mathrm{mg} / \mathrm{kg} \mathrm{HE}$ group, but not in $25 \mathrm{mg} / \mathrm{kg}$ HE group. Synaptophysin is a synaptic marker of neuroendocrine cells that participates in synaptic transmission, whereas nestin and doublecortin are common markers for neurogenesis and are generally expressed in developing neuronal progenitor cells during adult neurogenesis $[83,84]$. In our study, HE restored BDNF expression and upregulated TrkB, Syp, Nestin, and $D c x$, suggesting potential antidepressant-like effects in CRS animals through the enhancement of BDNF/TrkB signalling, eventually leading to neurogenesis.

To support the findings of the gene expression study, we performed Western blot analyses to examine expression levels of neuroplasticity-related proteins. The CRS + saline group showed remarkably lower TrkB, pTrkB, pCREB, and pERK1/2 protein expressions compared with the non-CRS control group. Decreased pCREB and pERK2 expression levels have been previously reported in the hippocampus and prefrontal cortex of stressed animals $[85,86]$. There were no significant differences in the expression levels of pro-BDNF, CREB, and ERK1/2 proteins between CRS + saline and non-CRS control groups, suggesting the expression levels of these proteins are not affected by CRS. However, $B d n f$ gene expression level was decreased in CRS animals. This may be attributed to the timeline of the animal sacrifice, in which transcribed mRNA had not been translated into proteins. Indeed, expression levels of BDNF, TrkB, and CREB proteins were reported to be decreased in post-mortem brains of suicide victims [87]. Additionally, lower plasma BDNF level was found to be associated with suicidal behaviour in major depressive disorder [88].
Our results showed that HE had robust antidepressant effects by reversing the reduced protein expression levels of mature BDNF and pCREB at $25 \mathrm{mg} / \mathrm{kg} \mathrm{HE}$, and rescued pTrkB at both 10 and $25 \mathrm{mg} / \mathrm{kg} \mathrm{HE}$. Although mature BDNF protein expression was not remarkably increased in the CRS $+10 \mathrm{mg} / \mathrm{kg}$ HE group compared to the CRS + saline group, $B d n f$ mRNA level was significantly increased in both 10 and $25 \mathrm{mg} / \mathrm{kg}$ HE treatment groups. This data suggests that $10 \mathrm{mg} / \mathrm{kg} \mathrm{HE}$ might require a longer period to increase the BDNF protein level in the dorsal hippocampus of CRS animals compared with $25 \mathrm{mg} / \mathrm{kg}$ HE. A previous study demonstrated that $200 \mathrm{mg} / \mathrm{kg}$ HE ethanol extract increased both BDNF and TrkB expression levels in mice after 4 weeks of treatment [23]. An increased hippocampal BDNF level is often reported in animals receiving antidepressants [89]. Furthermore, BDNF expression was also found to be elevated in the DG in the hippocampus at post-mortem in subjects on antidepressant treatments [87]. We found no changes in the protein expression level of pro-BDNF in the dorsal hippocampus of CRS animals treated with HE, which is in contrast to a previous clinical study that found 8 weeks of HE treatment significantly increased circulating pro-BDNF levels without significantly changing circulating BDNF levels [25]. This discrepancy could be due to the different treatment lengths or the different tissues collected for analysis. Based on the hypothesis that HE can modulate the protein expression levels of pro-BDNF and mature BDNF in different tissues, consideration should be given to the brain region or treatment length in future studies, as these proteins are well known to be associated with antidepressant-like effects. Additionally, many studies have identified the bioactive compounds of HE that stimulate NGF expression [26, 29-35], however, the bioactive compounds that contribute to increased BDNF expression have yet to be identified.

Interestingly, TrkB, CREB, and pERK protein expressions were elevated in CRS animals receiving $10 \mathrm{mg} / \mathrm{kg}$ HE, but not with $25 \mathrm{mg} / \mathrm{kg}$ HE. Similarly, previous studies demonstrated that antidepressants could restore the decreased expressions of pCREB and pERK2 in stressed animals, but not the expression of CREB and ERK [85, 86]. Therefore, it appears that the antidepressant effects of $\mathrm{HE}$ are specifically induced through the activation of TrkB, ERK, and CREB to elevate protein levels of pTrkB, pERK, and pCREB. These results suggest that the antidepressant-like effects of HE could be possibly mediated through a BDNF/TrkB/CREB signalling pathway, leading to hippocampal neurogenesis. Furthermore, our findings showed that HE stimulated the synthesis of BDNF. Overexpressed BDNF activates TrkB through phosphorylation and triggers the downstream MEK-ERK signalling cascade. This cascade leads to the phosphorylation 
of CREB, which is a major transcription factor regulating the expression of neuroplasticity-related genes, eventually promoting neurogenesis and neurite outgrowth [53]. Increased activities in the CREB cascade in the hippocampus have been shown to increase neurogenesis of dentate granule cell progenitors and dendritic length and branching, leading to an antidepressant-like response [90, 91]. Morphological analysis of neurogenesis marker BrdU showed increased newborn cell proliferation in the $10 \mathrm{mg} / \mathrm{kg}$ HE group, confirming its neurogenic effects. Indeed, these results are in line with previous reports that demonstrated antidepressants could selectively enhance cell proliferation in the DG [92]. However, we found decreased numbers of cells stained with both NeuN and BrdU in CRS animals receiving $25 \mathrm{mg} / \mathrm{kg} \mathrm{HE}$. This may imply that a chronic high dose of $25 \mathrm{mg} / \mathrm{kg}$ HE may delay or reduce cells differentiation into mature neurones, and that the antidepressant effects observed at $10 \mathrm{mg} / \mathrm{kg} \mathrm{HE}$ were attributed to neurogenesis-independent mechanisms. The unaffected $\mathrm{BrdU}^{+} / \mathrm{NeuN}^{+}$cell count in the $10 \mathrm{mg} / \mathrm{kg}$ HE group suggests the involvement of other cell types mediating the therapeutic effects of HE, such as neural stem cells or glial cells. Further histological investigations on the involvement of neural stem cells and immature neurones are highly warranted to examine the role of early phase neurogenesis in the antidepressant effects of HE.

The results of the gene and protein expression study and immunofluorescence staining suggest that the mechanism of antidepressant-like effects of HE may be mediated through a neurogenesis-dependent pathway. To determine whether the underlying mechanism is neurogenesis-dependent, we used a neurogenesis blocker TMZ to block hippocampal neurogenesis. This approach is commonly used to evaluate if behavioural responses are mediated through neurogenesis-dependent mechanisms [93-96]. Our results found no significant differences in all the behavioural tests among all TMZ-treated groups, implying the administration of the neurogenesis blocker completely abolished the antidepressant-like effects of HE. This result supports our hypothesis that the antidepressant-like effects of HE are mediated through a neurogenesis-dependent mechanism, which is in line with the previous finding of enhanced hippocampal neurogenesis after 4 weeks of $60 \mathrm{mg} / \mathrm{kg} \mathrm{HE}$ [22]. Additionally, several bioactive compounds isolated from HE, such as hericenones [30], erinacines [97], ergosterol peroxide, cerevisterol, and $3 \beta, 5 \alpha, 9 \alpha$-trihydroxy-ergosta-7,22-dien6-one39 [35], have been found to induce NGF-activity and enhance neuritogenesis, both of which were reported to be involved in alleviating depressive-like symptoms [98-103]. To further investigate the effects of HE, we conducted a correlation study of the depression-related behavioural tests. We found a significant positive correlation between the sucrose preference and immobility time in both CRS $+10 \mathrm{mg} / \mathrm{kg}$ HE and CRS $+25 \mathrm{mg} /$ $\mathrm{kg}$ HE groups and the non-CRS control group, but not in the CRS + saline group, suggesting HE rescues the behavioural despair in CRS animals. In contrast, no positive correlation was found for all TMZ groups, implying that neurogenesis blocker TMZ abolished the antidepressant effects of HE. We further examined the effects on neuroinflammation by analysing GFAP expression. We previously proposed that the anti-inflammatory activity of $\mathrm{HE}$ was part of multifactorial mechanisms underlying the therapeutic effects in depression [28]. The anti-inflammatory effects of HE have been widely reported, including reducing pro-inflammatory cytokines, increasing anti-inflammatory cytokines, and mitigating oxidative stress [20, 23]. Zhang et al. [58] used a transgenic animal model that is prone to astrocyte activation to show hyperactivate astrocytes contributed to the secretion of pro-inflammatory factors such as interleukin- 6 and tumour necrosis factor $\alpha$ (TNF- $\alpha$ ), which were associated with depressive behaviour. In our study, we found that hippocampal $\mathrm{GFAP}^{+}$astrocytes were reduced in CRS animals treated with 10 and $25 \mathrm{mg} / \mathrm{kg}$ HE. This result is in line with the previous finding that amycenone, a bioactive compound isolated from HE, attenuated TNF- $\alpha$ in an LPS-induced inflammation model of depression [21], suggesting that $\mathrm{HE}$ can alleviate neuroinflammation by suppressing astrocyte activation. Moreover, TMZ administration completely abolished the suppressive effects of $\mathrm{HE}$, further strengthening the evidence for the neurogenesis-dependent therapeutic effects of HE.

In conclusion, our study showed that 4 weeks of intraperitoneal administration of HE alleviated depressivelike behaviours in a CRS model of depression. Taken together, the present findings showed the HE treatment induced antidepressant and anti-inflammatory effects via a neurogenesis-dependent mechanism. We found that $\mathrm{HE}$ rescued behavioural despair possibly through a BDNF-TrkB-CREB signalling mechanism, leading to increased hippocampal neurogenesis and decreased neuroinflammation that contribute to the antidepressant effects.

\footnotetext{
Abbreviations

AKT: Protein kinase B; BDNF: Brain-derived neurotrophic factor; BrdU: Bromodeoxyuridine; CA: Cornu Ammonis; CREB: CAMP response element-binding protein; CRS: Chronic restraint stress; DCX: Doublecortin; DG: Dentate gyrus; DPPH: 2,2-Diphenyl-1-picrylhydrazyl; ERK: Extracellular signal-regulated kinase; FRAP: Ferric reducing antioxidant power; GAPDH: Glyceraldehyde 3-phosphate dehydrogenase; GFAP: Glial fibrillary acidic protein; HE: Hericium erinaceus; HPLC: High-performance liquid chromatography; Nes: Nestin; NeuN: Neuronal nuclei; NGF: Nerve growth factor; PSD-95: Postsynaptic density protein 95; SYN: Synapsin; TMZ: Temozolomide; TNF-a: Tumour necrosis factor a; TrkB: Tropomyosin receptor kinase B.
} 


\section{Supplementary Information}

The online version contains supplementary material available at https://doi. org/10.1186/s13020-021-00546-8.

Additional file 1: Fig. S1. NMR data assignments. Schematic diagram of the chemical structure of herierin IV (A). Steps involved in the isolation of HE compounds (B). Fig. S2. Visualization of MAPK (A) and IL-17 (B) signalling pathways. Fig. S3. Visualization of TNF (A) and neurotrophin (B) signalling pathways.

Additional file 2: Table S1. ${ }^{1} \mathrm{H}$ and ${ }^{13} \mathrm{C}$ NMR $(600 \mathrm{MHz})$ spectroscopic data for herierin IV (3) in $\mathrm{MeOH}_{-}{ }_{\mathrm{d} 4}$

\section{Acknowledgements}

We thank PGC for the support of H. erinaceus compound and partial funding for the research project.

\section{Authors' contributions}

Conceptualisation and study design, funding/resources, data analysis, supervision, editing and revision: KHW and LWL. Original draft preparation, data analysis, and preparation of figures: PSC, CHP, and LWL. Experimental data collection and analysis: SYL, MWLP, and KHW (Fig. 1, Table 2, Additional file 2: Table S1 and Additional file 1: Fig. S1); KCT (Figs. 1, 2, Additional file 1: Figs. S2, S3); PSC CHP, and JR (Fig. 3); PSC (Figs. 4, 5, 6, 7, 8, 9); PSC and KCT (Fig. 7); and PSC, SYL, MWLP, and RJYT (Fig. 9). Revision of the manuscript: CHP, PSC, KCT, SYL, KHW, and LWL. Research Funding: MLF and LWL. All authors provided substantial intellectual inputs. All authors read and approved the final manuscript.

\section{Funding}

The scientific study was funded by grants from the Hong Kong Research Grants Council (UGC-RMGS, Ref. 207301003), and the Seed Fund for Translational and Applied Research (Ref. 104005226) awarded to L.W.L. The scientific works were conducted at the Neuromodulation Laboratory (www.drlimlab. com), the University of Hong Kong.

\section{Availability of data and materials}

The datasets from and/or analysed during the current study are available from the corresponding author on reasonable request.

\section{Declarations}

Ethics approval and consent to participate Not applicable.

\section{Consent for publication}

Not applicable.

\section{Competing interests}

Ganofarm R\&D Sdn Bhd supplied the standardised extract of HE (Memorandum of Understanding for Academic Cooperation between Universiti Malaya and Ganofarm R\&D Sdn Bhd dated 20 August 2018). The authors declare that the research was conducted in the absence of any commercial or financial relationships that may bias the data interpretation and scientific output. This company had no role in the study design and conceptualisation, data collection/analysis, interpretation, and scientific writing of this work.

\section{Author details}

${ }^{1}$ Neuromodulation Laboratory, School of Biomedical Sciences, Li Ka Shing Faculty of Medicine, The University of Hong Kong, 21 Sassoon Road, Hong Kong SAR, China. ${ }^{2}$ Department of Anatomy, Faculty of Medicine, Universiti Malaya, 50603 Kuala Lumpur, Malaysia. ${ }^{3}$ Institute of Biological Sciences, Faculty of Science, Universiti Malaya, 50603 Kuala Lumpur, Malaysia. ${ }^{4}$ Ganofarm R\&D SDN BHD, 01-01, SKYPOD SQUARE, Persiaran Puchong Jaya Selatan, Bandar Puchong Jaya, 47100 Puchong, Selangor, Malaysia.

Received: 13 September 2021 Accepted: 27 November 2021

Published online: 07 December 2021
References

1. GBD 2017 Disease and Injury Incidence and Prevalence Collaborators. Global, regional, and national incidence, prevalence, and years lived with disability for 354 diseases and injuries for 195 countries and territories, 1990-2017: a systematic analysis for the Global Burden of Disease Study 2017. Lancet. 2018;392(10159):1789-858

2. Bartolomucci A, Leopardi R. Stress and depression: preclinical research and clinical implications. PLoS ONE. 2009;4(1): e4265

3. Kanter JW, Busch AM, Weeks CE, Landes SJ. The nature of clinical depression: symptoms, syndromes, and behavior analysis. Behav Anal. 2008;31(1):1-21.

4. Jokela M, Virtanen M, Batty GD, Kivimäki M. Inflammation and specific symptoms of depression. JAMA Psychiat. 2016;73(1):87-8.

5. McMahon FJ, Buervenich S, Charney D, Lipsky R, Rush AJ, Wilson AF, et al. Variation in the gene encoding the serotonin $2 \mathrm{~A}$ receptor is associated with outcome of antidepressant treatment. Am J Hum Genet. 2006;78(5):804-14.

6. Hasler G. Pathophysiology of depression: do we have any solid evidence of interest to clinicians? World Psychiatry. 2010;9(3):155-61.

7. Little A. Treatment-resistant depression. Am Fam Phys. 2009;80(2):167-72.

8. Keks N, Hope J, Keogh S. Switching and stopping antidepressants. Aust Prescr. 2016:39(3):76-83.

9. Keks NA, Hope J, Culhane C. Management of antidepressant-induced sexual dysfunction. Australas Psychiatry. 2014;22(6):525-8.

10. Qureshi NA, Al-Bedah AM. Mood disorders and complementary and alternative medicine: a literature review. Neuropsychiatr Dis Treat. 2013;9:639-58

11. Mori K, Ouchi K, Hirasawa N. The anti-inflammatory effects of lion's mane culinary-medicinal mushroom, Hericium erinaceus (Higher Basidiomycetes) in a coculture system of 3T3-L1 adipocytes and RAW264 macrophages. Int J Med Mushrooms. 2015;17(7):609-18.

12. Wang JC, Hu SH, Su CH, Lee TM. Antitumor and immunoenhancing activities of polysaccharide from culture broth of Hericium spp. Kaohsiung J Med Sci. 2001;17(9):461-7.

13. Zhang Z, Liu RN, Tang QJ, Zhang JS, Yang Y, Shang XD. A new diterpene from the fungal mycelia of Hericium erinaceus. Phytochem Lett. 2015;11:151-6.

14. Yi Z, Shao-Long Y, Ai-Hong W, Zhi-Chun S, Ya-Fen Z, Ye-Ting X, et al. Protective effect of ethanol extracts of Hericium erinaceus on alloxaninduced diabetic neuropathic pain in rats. Evid Based Complement Alternat Med. 2015:2015: 595480.

15. Rahman MA, Abdullah N, Aminudin N. Inhibitory effect on in vitro LDL oxidation and HMG Co-A reductase activity of the liquid-liquid partitioned fractions of Hericium erinaceus (Bull.) Persoon (lion's mane mushroom). Biomed Res Int. 2014;2014: 828149.

16. Liang B, Guo Z, Xie F, Zhao A. Antihyperglycemic and antihyperlipidemic activities of aqueous extract of Hericium erinaceus in experimental diabetic rats. BMC Complement Altern Med. 2013:13:253.

17. Yang BK, Park JB, Song CH. Hypolipidemic effect of an exo-biopolymer produced from a submerged mycelial culture of Hericium erinaceus. Biosci Biotechnol Biochem. 2003;67(6):1292-8.

18. Mori K, Inatomi S, Ouchi K, Azumi Y, Tuchida T. Improving effects of the mushroom Yamabushitake (Hericium erinaceus) on mild cognitive impairment: a double-blind placebo-controlled clinical trial. Phytother Res. 2009;23(3):367-72.

19. Tsai-Teng T, Chin-Chu C, Li-Ya L, Wan-Ping C, Chung-Kuang L, ChienChang $S$, et al. Erinacine A-enriched Hericium erinaceus mycelium ameliorates Alzheimer's disease-related pathologies in APPswe/ PS1dE9 transgenic mice. J Biomed Sci. 2016;23(1):49.

20. Kuo HC, Lu CC, Shen CH, Tung SY, Hsieh MC, Lee KC, et al. Hericium erinaceus mycelium and its isolated erinacine $\mathrm{A}$ protection from MPTP-induced neurotoxicity through the ER stress, triggering an apoptosis cascade. J Transl Med. 2016;14(1):78.

21. Yao W, Zhang JC, Dong C, Zhuang C, Hirota S, Inanaga K, et al. Effects of amycenone on serum levels of tumor necrosis factor-alpha, interleukin-10, and depression-like behavior in mice after lipopolysaccharide administration. Pharmacol Biochem Behav. 2015;136:7-12.

22. Ryu S, Kim HG, Kim JY, Kim SY, Cho KO. Hericium erinaceus extract reduces anxiety and depressive behaviors by promoting 
hippocampal neurogenesis in the adult mouse brain. J Med Food. 2018;21(2):174-80

23. Chiu CH, Chyau CC, Chen CC, Lee LY, Chen WP, Liu JL, et al. Erinacine A-enriched Hericium erinaceus mycelium produces antidepressantlike effects through modulating BDNF/PI3K/Akt/GSK-3beta signaling in mice. Int J Mol Sci. 2018. https://doi.org/10.3390/ijms19020341.

24. Inanaga K. Marked improvement of neurocognitive impairment after treatment with compounds from Hericium erinaceum: a case study of recurrent depressive disorder. Pers Med Universe. 2014:3:46-8.

25. Vigna L, Morelli F, Agnelli GM, Napolitano F, Ratto D, Occhinegro $A$, et al. Hericium erinaceus improves mood and sleep disorders in patients affected by overweight or obesity: could circulating proBDNF and BDNF be potential biomarkers? Evid Based Complement Alternat Med. 2019:2019:7861297.

26. Okamura H, Anno N, Tsuda A, Inokuchi T, Uchimura N, Inanaga K. The effects of Hericium erinaceus (Amyloban ${ }^{\circledR}$ 3399) on sleep quality and subjective well-being among female undergraduate students: a pilot study. Pers Med Universe. 2015;4:76-8.

27. Nagano M, Shimizu K, Kondo R, Hayashi C, Sato D, Kitagawa K, et al. Reduction of depression and anxiety by 4 weeks Hericium erinaceus intake. Biomed Res. 2010;31(4):231-7.

28. Chong PS, Fung ML, Wong KH, Lim LW. Therapeutic potential of Hericium erinaceus for depressive disorder. Int J Mol Sci. 2019. https:// doi.org/10.3390/ijms21010163.

29. Ma B-J, Shen J-W, Yu H-Y, Ruan Y, Wu T-T, Zhao X. Hericenones and erinacines: stimulators of nerve growth factor (NGF) biosynthesis in Hericium erinaceus. Mycology. 2010;1 (2):92-8.

30. Kawagishi $H$, Ando M, Sakamoto H, Yoshida S, Ojima F, Ishiguro $Y$, et al. Hericenones $C, D$ and $E$, stimulators of nerve growth factor (NGF)-synthesis, from the mushroom Hericium erinaceum. Tetrahedron Lett. 1991:32(35):4561-4.

31. Shimbo M, Kawagishi H, Yokogoshi $H$. Erinacine A increases catecholamine and nerve growth factor content in the central nervous system of rats. Nutr Res. 2005;25(6):617-23.

32. Kawagishi H, Shimada A, Hosokawa S, Mori H, Sakamoto H, Ishiguro Y, et al. Erinacines $E$, F, and $G$, stimulators of nerve growth factor (NGF)synthesis, from the mycelia of Hericium erinaceum. Tetrahedron Lett. 1996:37(41):7399-402.

33. Kawagishi H, Masui A, Tokuyama S, Nakamura T. Erinacines J and $\mathrm{K}$ from the mycelia of Hericium erinaceum. Tetrahedron. 2006;62(36):8463-6.

34. Chen CC, Tzeng TT, Chen CC, Ni CL, Lee LY, Chen WP, et al. Erinacine $\mathrm{S}$, a Rare Sesterterpene from the Mycelia of Hericium erinaceus. J Nat Prod. 2016;79(2):438-41.

35. Zhang CC, Yin X, Cao CY, Wei J, Zhang Q, Gao JM. Chemical constituents from Hericium erinaceus and their ability to stimulate NGFmediated neurite outgrowth on PC12 cells. Bioorg Med Chem Lett. 2015;25(22):5078-82.

36. Lew S-Y, Yow Y-Y, Lim LW, Wong K-H. Antioxidant-mediated protective role of Hericium erinaceus (Bull.: Fr.) Pers. against oxidative damage in fibroblasts from Friedreich's ataxia patient. Food Sci Technol. 2019. https://doi.org/10.1590/fst.09919.

37. Lew SY, Lim SH, Lim LW, Wong KH. Neuroprotective effects of Hericium erinaceus (Bull.: Fr.) Pers. against high-dose corticosteroneinduced oxidative stress in PC-12 cells. BMC Complement Med Ther. 2020;20(1):340

38. Lee SR, Yi SA, Nam KH, Ryoo R, Lee J, Kim KH. Pantheric acids A-C from a poisonous mushroom, Amanita pantherina, promote lipid accumulation in adipocytes. J Nat Prod. 2019;82(12):3489-93.

39. Singleton VL, Rossi JA. Colorimetry of total phenolics with phosphomolybdic-phosphotungstic acid reagents. Am J Enol Vitic 1965:16(3):144-58.

40. George DS, Razali Z, Santhirasegaram V, Somasundram C. Effects of ultraviolet light (UV-C) and heat treatment on the quality of fresh-cut Chokanan Mango and Josephine Pineapple. J Food Sci. 2015:80(2):S426-34

41. Sakanaka S, Tachibana Y, Okada Y. Preparation and antioxidant properties of extracts of Japanese persimmon leaf tea (kakinoha-cha). Food Chem. 2005;89(4):569-75.

42. Santhirasegaram V, Razali Z, George DS, Somasundram C. Comparison of UV-C treatment and thermal pasteurization on quality of
Chokanan mango (Mangifera indica L.) juice. Food Bioproducts Process. 2015;94:313-21.

43. Prieto $P$, Pineda M, Aguilar M. Spectrophotometric quantitation of antioxidant capacity through the formation of a phosphomolybdenum complex: specific application to the determination of vitamin E. Anal Biochem. 1999;269(2):337-41.

44. Siger A, Nogala-Kalucka M, Lampart-Szczapa E. The content and antioxidant activity of phenolic compounds in cold-pressed plant oils. J Food Lipids. 2008:15(2):137-49.

45. Benzie IF, Strain JJ. The ferric reducing ability of plasma (FRAP) as a measure of "antioxidant power": the FRAP assay. Anal Biochem. 1996;239(1):70-6.

46. Lim LW, Prickaerts J, Huguet G, Kadar E, Hartung H, Sharp T, et al. Electrical stimulation alleviates depressive-like behaviors of rats: investigation of brain targets and potential mechanisms. Transl Psychiatry. 2015;5(3): e535.

47. Lim LW, Shrestha S, Or YZ, Tan SZ, Chung HH, Sun Y, et al. Tetratricopeptide repeat domain 9A modulates anxiety-like behavior in female mice. Sci Rep. 2016;6:37568.

48. Tan SZK, Poon CH, Chan YS, Lim LW. Prelimbic cortical stimulation disrupts fear memory consolidation through ventral hippocampal dopamine 2 receptors. Br J Pharmacol. 2021. https://doi.org/10.1111/ bph.15505.

49. Livak KJ, Schmittgen TD. Analysis of relative gene expression data using real-time quantitative PCR and the 2(-Delta Delta C(T)) method. Methods. 2001;25(4):402-8

50. Qin T, Ren Z, Huang Y, Song Y, Lin D, Li J, et al. Selenizing Hericium erinaceus polysaccharides induces dendritic cells maturation through MAPK and NF-kappaB signaling pathways. Int J Biol Macromol. 2017;97:287-98

51. Diling C, Chaoqun Z, Jian Y, Jian L, Jiyan S, Yizhen X, et al. Immunomodulatory activities of a fungal protein extracted from Hericium erinaceus through regulating the gut microbiota. Front Immunol. 2017;8:666.

52. Lai PL, Naidu M, Sabaratnam V, Wong KH, David RP, Kuppusamy UR, et al. Neurotrophic properties of the Lion's mane medicinal mushroom, Hericium erinaceus (Higher Basidiomycetes) from Malaysia. Int J Med Mushrooms. 2013;15(6):539-54

53. Poon $\mathrm{CH}$, Heng BC, Lim LW. New insights on brain-derived neurotrophic factor epigenetics: from depression to memory extinction. Ann NY Acad Sci. 2021;1484(1):9-31.

54. Lipsky RH, Marini AM. Brain-derived neurotrophic factor in neuronal survival and behavior-related plasticity. Ann N Y Acad Sci. 2007;1122(1):130-43.

55. Impey S, Obrietan K, Wong ST, Poser S, Yano S, Wayman G, et al. Cross talk between ERK and PKA is required for $\mathrm{Ca} 2+$ stimulation of CREB-dependent transcription and ERK nuclear translocation. Neuron. 1998;21(4):869-83.

56. Dong Y, Pu K, Duan W, Chen H, Chen L, Wang Y. Involvement of Akt/ CREB signaling pathways in the protective effect of EPA against interleukin-1 beta-induced cytotoxicity and BDNF down-regulation in cultured rat hippocampal neurons. BMC Neurosci. 2018:19(1):52.

57. Ruan L, Lau BW, Wang J, Huang L, Zhuge Q, Wang B, et al. Neurogenesis in neurological and psychiatric diseases and brain injury: from bench to bedside. Prog Neurobiol. 2014;115:116-37.

58. Zhang $\mathrm{HY}$, Wang $\mathrm{Y}, \mathrm{He} Y$, Wang $\mathrm{T}$, Huang $\mathrm{XH}$, Zhao $\mathrm{CM}$, et al. A1 astrocytes contribute to murine depression-like behavior and cognitive dysfunction, which can be alleviated by IL-10 or fluorocitrate treatment. J Neuroinflammation. 2020;17(1):200.

59. Schiepers OJ, Wichers MC, Maes M. Cytokines and major depression. Prog Neuropsychopharmacol Biol Psychiatry. 2005;29(2):201-17.

60. Brites D, Fernandes A. Neuroinflammation and depression: microglia activation, extracellular microvesicles and microRNA dysregulation. Front Cell Neurosci. 2015;9:476.

61. Lew SY, Teoh SL, Lim SH, Lim LW, Wong KH. Discovering the potentials of medicinal mushrooms in combating depression-a review. Mini Rev Med Chem. 2020;20(15):1518-31.

62. An G-H, Han J-G, Lee K-H, Cho J-H. Comparison of physiological activity of medicinal mushrooms produced in Korea and China using different extraction solvents. J Mushroom. 2019;17(1):34-9. 
63. Kim DH, Park SR, Debnath T, Hasnat MA, Pervin M, Lim BO. Evaluation of the antioxidant activity and anti-inflammatory effect of Hericium erinaceus water extracts. Korean J Med Crop Sci. 2013;21(2):112-7.

64. Lee YM, Kim IS, Ghosh M, Hong SM, Lee TH, Lee DH, et al. Antioxidant activity and $\mathrm{NO}$ inhibitory effect of bioconverted medicinal material using germinated green rice and Hericium erinaceus mycelium. Korean J Med Crop Sci. 2017;25(5):305-14.

65. Yildiz O, Can Z, Laghari AQ, Şahin H, Malkoç M. Wild edible mushrooms as a natural source of phenolics and antioxidants. J Food Biochem. 2015;39(2):148-54.

66. Charumathy M, Sudha G, Balakrishnan P. Detection of antioxidant activity and bioactive constituents in the fruiting bodies of Hericium erinaceus pers-an edible mushroom. J Pharm Pham Sci. 2016;8:152-6.

67. Li H, Park S, Moon B, Yoo Y-B, Lee Y-W, Lee C. Targeted phenolic analysis in Hericium erinaceum and its antioxidant activities. Food Sci Biotechnol. 2012;21(3):881-8.

68. Jiang $S$, Wang $Y$, Zhang $X$. Comparative studies on extracts from Hericium erinaceus by different polarity reagents to gain higher antioxidant activities. Exp Ther Med. 2016;12(1):513-7.

69. Islam T, Yu X, Xu B. Phenolic profiles, antioxidant capacities and metal chelating ability of edible mushrooms commonly consumed in China. LWT Food Sci Technol. 2016;72:423-31.

70. Wang $Y, X u$ B. Distribution of antioxidant activities and total phenolic contents in acetone, ethanol, water and hot water extracts from 20 edible mushrooms via sequential extraction. Austin J Nutri Food Sci. 2014;2(1):1009.

71. Qian FG, Xu GY, Du SJ, Li MH. Isolation and identification of two new pyrone compounds from the culture of Herictum erinaceus. Yao Xue Xue Bao. 1990;25(7):522-5.

72. Lu QQ, Tian JM, Wei J, Gao JM. Bioactive metabolites from the mycelia of the basidiomycete Hericium erinaceum. Nat Prod Res. 2014;28(16):1288-92.

73. Zhang CC, Cao CY, Kubo M, Harada K, Yan XT, Fukuyama Y, et al. Chemical constituents from Hericium erinaceus promote neuronal survival and potentiate neurite outgrowth via the TrkA/Erk1/2 pathway. Int J Mol Sci. 2017. https://doi.org/10.3390/ijms18081659.

74. Lv G, Song X, Zhang Z. Protective effect of the ethanol extract from Hericium erinaceus against ethanol-induced gastric ulcers. Pol J Food Nutr Sci. 2021;71(3):333-41.

75. Duric V, Banasr M, Licznerski P, Schmidt HD, Stockmeier CA, Simen AA et al. A negative regulator of MAP kinase causes depressive behavior. Nat Med. 2010;16(11):1328-32.

76. Himmerich H, Patsalos O, Lichtblau N, Ibrahim MAA, Dalton B. Cytokine research in depression: principles, challenges, and open questions. Front Psychiatry. 2019;10:30.

77. Kenis G, Maes M. Effects of antidepressants on the production of cytokines. Int J Neuropsychopharmacol. 2002;5(4):401-12.

78. Overstreet DH, Fredericks K, Knapp D, Breese G, McMichael J. Nerve growth factor (NGF) has novel antidepressant-like properties in rats. Pharmacol Biochem Behav. 2010;94(4):553-60.

79. Post RM. Role of BDNF in bipolar and unipolar disorder: clinical and theoretical implications. J Psychiatr Res. 2007;41(12):979-90.

80. $\mathrm{Yu} \mathrm{H}$, Chen ZY. The role of BDNF in depression on the basis of its location in the neural circuitry. Acta Pharmacol Sin. 2011;32(1):3-11.

81. Monteggia LM, Luikart B, Barrot M, Theobold D, Malkovska I, Nef S, et al. Brain-derived neurotrophic factor conditional knockouts show gender differences in depression-related behaviors. Biol Psychiatry. 2007:61(2):187-97.

82. Berton O, Nestler EJ. New approaches to antidepressant drug discovery: beyond monoamines. Nat Rev Neurosci. 2006;7(2):137-51.

83. Bernal A, Arranz L. Nestin-expressing progenitor cells: function, identity and therapeutic implications. Cell Mol Life Sci. 2018:75(12):2177-95.

84. Brown JP, Couillard-Despres S, Cooper-Kuhn CM, Winkler J, Aigner L, Kuhn HG. Transient expression of doublecortin during adult neurogenesis. J Comp Neurol. 2003;467(1):1-10.

85. Sairanen M, O'Leary OF, Knuuttila JE, Castren E. Chronic antidepressant treatment selectively increases expression of plasticity-related proteins in the hippocampus and medial prefrontal cortex of the rat. Neuroscience. 2007;144(1):368-74

86. Qi X, Lin W, Li J, Li H, Wang W, Wang D, et al. Fluoxetine increases the activity of the ERK-CREB signal system and alleviates the depressive-like behavior in rats exposed to chronic forced swim stress. Neurobiol Dis. 2008;31(2):278-85.

87. Dwivedi Y, Rao JS, Rizavi HS, Kotowski J, Conley RR, Roberts RC, et al. Abnormal expression and functional characteristics of cyclic adenosine monophosphate response element binding protein in postmortem brain of suicide subjects. Arch Gen Psychiatry. 2003;60(3):273-82.

88. Kim YK, Lee HP, Won SD, Park EY, Lee HY, Lee BH, et al. Low plasma BDNF is associated with suicidal behavior in major depression. Prog Neuropsychopharmacol Biol Psychiatry. 2007;31(1):78-85.

89. Russo-Neustadt AA, Chen MJ. Brain-derived neurotrophic factor and antidepressant activity. Curr Pharm Des. 2005;11(12):1495-510.

90. Fujioka T, Fujioka A, Duman RS. Activation of cAMP signaling facilitates the morphological maturation of newborn neurons in adult hippocampus. J Neurosci. 2004;24(2):319-28.

91. Duman RS. Pathophysiology of depression: the concept of synaptic plasticity. Eur Psychiatry. 2002;17(Suppl 3):306-10.

92. Malberg JE, Eisch AJ, Nestler EJ, Duman RS. Chronic antidepressant treatment increases neurogenesis in adult rat hippocampus. J Neurosci. 2000;20(24):9104-10.

93. Niibori Y, Yu TS, Epp JR, Akers KG, Josselyn SA, Frankland PW. Suppression of adult neurogenesis impairs population coding of similar contexts in hippocampal CA3 region. Nat Commun. 2012;3:1253.

94. Egeland M, Guinaudie C, Du Preez A, Musaelyan K, Zunszain PA, Fernandes $C$, et al. Depletion of adult neurogenesis using the chemotherapy drug temozolomide in mice induces behavioural and biological changes relevant to depression. Transl Psychiatry. 2017;7(4): e1101.

95. Bambico FR, Bregman T, Diwan M, Li J, Darvish-Ghane S, Li Z, et al. Neuroplasticity-dependent and -independent mechanisms of chronic deep brain stimulation in stressed rats. Transl Psychiatry. 2015;5: e674.

96. Jessberger S, Kempermann G. Adult-born hippocampal neurons mature into activity-dependent responsiveness. Eur J Neurosci. 2003;18(10):2707-12

97. Kawagishi H, Shimada A, Shirai R, Okamoto K, Ojima F, Sakamoto H, et al. Erinacines A, B and C, strong stimulators of nerve growth factor (NGF)-synthesis, from the mycelia of Hericium erinaceum. Tetrahedron Lett. 1994:35(10):1569-72.

98. Drevets WC. Neuroimaging and neuropathological studies of depression: implications for the cognitive-emotional features of mood disorders. Curr Opin Neurobiol. 2001;11(2):240-9.

99. Hastings RS, Parsey RV, Oquendo MA, Arango V, Mann JJ. Volumetric analysis of the prefrontal cortex, amygdala, and hippocampus in major depression. Neuropsychopharmacology. 2004;29(5):952-9.

100. MacQueen GM, Campbell S, McEwen BS, Macdonald K, Amano S, Joffe RT, et al. Course of illness, hippocampal function, and hippocampal volume in major depression. Focus. 2003:3(1):146-55.

101. Vermetten E, Vythilingam M, Southwick SM, Charney DS, Bremner JD. Long-term treatment with paroxetine increases verbal declarative memory and hippocampal volume in posttraumatic stress disorder. Biol Psychiatry. 2003;54(7):693-702.

102. Lee R, Kermani P, Teng KK, Hempstead BL. Regulation of cell survival by secreted proneurotrophins. Science. 2001:294(5548):1945-8.

103. Skaper SD. The biology of neurotrophins, signalling pathways, and functional peptide mimetics of neurotrophins and their receptors. CNS Neurol Disord Drug Targets. 2008;7(1):46-62.

104. Xu H, Zhang Y, Zhang F, Yuan SN, Shao F, Wang W. Effects of duloxetine treatment on cognitive flexibility and BDNF expression in the MPFC of adult male mice exposed to social stress during adolescence. Front $\mathrm{Mol}$ Neurosci. 2016:9:95

105. Wagner N, Wagner KD, Theres H, Englert C, Schedl A, Scholz H. Coronary vessel development requires activation of the TrkB neurotrophin receptor by the Wilms' tumor transcription factor Wt1. Genes Dev. 2005:19(21):2631-42.

106. Wang HY, Hsieh PF, Huang DF, Chin PS, Chou CH, Tung CC, et al. RBFOX3/NeuN is required for hippocampal circuit balance and function. Sci Rep. 2015;5:17383.

107. Wong YW, Schulze C, Streichert T, Gronostajski RM, Schachner M, Tilling T. Gene expression analysis of nuclear factor I-A deficient mice indicates delayed brain maturation. Genome Biol. 2007;8(5):R72. 
108. Araujo APB, Diniz LP, Eller CM, de Matos BG, Martinez R, Gomes FCA. Effects of transforming growth factor beta 1 in cerebellar development: role in synapse formation. Front Cell Neurosci. 2016;10:104. https://doi. org/10.3389/fncel.2016.00104.

109. Konirova J, Oltova J, Corlett A, Kopycinska J, Kolar M, Bartunek P, et al. Modulated DISP3/PTCHD2 expression influences neural stem cell fate decisions. Sci Rep. 2017;7:41597.

110. Pan W, Han S, Kang L, Li S, Du J, Cui H. Effects of dihydrotestosterone on synaptic plasticity of the hippocampus in mild cognitive impairment male SAMP8 mice. Exp Ther Med. 2016;12(3):1455-63.

111. Kerr B, Silva PA, Walz K, Young Jl. Unconventional transcriptional response to environmental enrichment in a mouse model of Rett syndrome. PLoS ONE. 2010;5(7): e11534.

\section{Publisher's Note}

Springer Nature remains neutral with regard to jurisdictional claims in published maps and institutional affiliations.

- fast, convenient online submission

- thorough peer review by experienced researchers in your field

- rapid publication on acceptance

- support for research data, including large and complex data types

- gold Open Access which fosters wider collaboration and increased citations

- maximum visibility for your research: over 100M website views per year

At BMC, research is always in progress.

Learn more biomedcentral.com/submissions 